\title{
Uma Pesquisa-Ação no Contexto de Processos de Engenharia de Requisitos em uma Instituição Pública Brasileira
}

\section{Title: An Action Research for User Requirements Processes in a Brazilian Public Institution}

\author{
Luís E. S. Santos ${ }^{1}$, Michel S. Soares ${ }^{1}$ \\ ${ }^{1}$ Postgraduate Program in Computer Science - PROCC \\ Federal University of Sergipe, Brazil \\ luiseduardo@ufs.br, micheledcomp.ufs.br
}

\begin{abstract}
Requirements Engineering stands out as a key phase within Software Engineering for establishing a strict and common vision between the client and the project team on software requirements. This study was carried out using the action research methodology in a public institution, with the goal of proposing and applying a user requirements elicitation and documentation process. In the process, a template is used for documenting requirements using SysML (Systems Modeling Language). Both qualitative and quantitative evaluations were carried out to evaluate the effectiveness of the process. Results suggest that the intervention achieved positive results, including evidence of improvements in user requirements elicitation and documentation.
\end{abstract}

Keywords. Action Research; Public Sector; Requirements Documentation; Requirements Engineering; SysML; User Requirements.

Resumo. A Engenharia de Requisitos se destaca como uma fase fundamental na Engenharia de Software por instituir uma visão estrita e comum entre o cliente e a equipe do projeto sobre os requisitos do software a ser desenvolvido. Este estudo foi realizado utilizando a metodologia de pesquisa-ação em uma instituição pública, com objetivo de propor e aplicar um processo para elicitação e documentação de requisitos em nível de usuário. No processo, um modelo foi usado para documentar os requisitos usando a SysML (Systems Modeling Language). No estudo foi realizada uma avaliação qualitativa e quantitativa para avaliar a eficácia do processo. Os resultados sugerem que a intervenção alcançou resultados positivos, incluindo evidências de melhorias na elicitação e documentação dos requisitos do usuário.

Palavras-Chave. Documentação de Requisitos; Engenharia Requisitos; Pesquisa-ação; Requisitos em nível de usuário; Setor Público; SysML. 


\section{Introdução}

A Engenharia de Requisitos (ER) tem sido objeto de discussão e estudo na Engenharia de Software, e sua importância é reconhecida desde meados da década de oitenta do século passado [Brooks 1987][Berry 2004][Mafra et al. 2016]. Segundo o IEEE, a ER é uma fase interdisciplinar que faz a mediação entre os domínios do usuário e desenvolvedor para estabelecer e manter os requisitos a serem atendidos pelo sistema, software ou serviço [ISO 2011]. A ER envolve atividades como o estudo da viabilidade, elicitação, documentação, validação, especificação e gerenciamento dos requisitos de um software [Van Lamsweerde 2000].

Entre os problemas encontrados na ER, os relacionados à documentação de requisitos, que muitas vezes é realizada de forma incompleta e de difícil compreensão pelos envolvidos no projeto, continuam como desafios a serem superados [Hall et al. 2002][Mafra et al. 2016]. As principais causas de problemas relacionados à documentação de requisitos em um projeto de software são falhas de comunicação entre equipe de desenvolvimento e o cliente; utilização ineficiente de um processo bem definido para realizar ER; utilização de técnicas de elicitação de requisitos deficientes; utilização deficiente ou não utilização de um modelo para documentação dos requisitos e a falta de especialistas em requisitos envolvidos no projeto [Fernández et al. 2015][Mafra et al. 2016].

Elicitação e documentação de requisitos são atividades iniciais que consistem na definição das funcionalidades que serão criadas para o software [Pressman and Maxim 2016][Braude and Bernstein 2016]. Os requisitos em nível de usuário são focados no domínio do problema e são o principal meio de comunicação entre os clientes e os desenvolvedores [Paech et al. 2005]. Os requisitos devem ser revisados e aprovados por todos os envolvidos nessa etapa [Sommerville 2011]. A documentação de requisitos em nível de usuário é utilizada em todas as fases do ciclo de vida do desenvolvimento do software, desde as fases iniciais até a homologação e entrega do produto final [Laplante 2013][Wiegers and Beatty 2013][Braude and Bernstein 2016].

A partir da documentação de requisitos em nível de usuário, outros artefatos como especificação de requisitos em nível de sistema podem ser utilizados para apoiar outras fases da Engenharia de Software, como a fase de desenvolvimento e testes de software quando são criados o código fonte e os casos de teste [Pohl 2010][Buede and Miller 2016]. Sendo assim, os defeitos gerados a partir de erros inseridos em um documento de requisitos podem ser catastróficos para um projeto de software, devido ao efeito cascata gerado pelo uso desse documento em todas as fases do processo [Berry 2004]. Erros nos documentos de requisitos podem proliferar pelas várias fases do processo de desenvolvimento, levando a um software de baixa qualidade [Ellis and Berry 2013]. É importante que os requisitos sejam capazes de transmitir com clareza os objetivos do usuário, que sejam de fácil manutencão e possibilitem aos engenheiros de software validar sua implementação [ISO 2011].

Para documentar os requisitos de forma eficiente, a UML (Unified Modeling Language) se destaca por ser atualmente a linguagem de modelagem mais utilizada na indústria de software [Hutchinson et al. 2011][Hutchinson et al. 2014][Störrle 2017]. 
Porém, outras técnicas e linguagens são frequentemente estudadas pela academia por apresentarem funcionalidades que aprimoram ou complementam outras linguagens e técnicas, a exemplo da SysML (Systems Modeling Language), que é uma extensão da UML, que possui diagramas específicos para modelar requisitos [SysML 2015].

A SysML é uma linguagem com o propósito de especificar, analisar, projetar e verificar softwares complexos, mitigando uma série de problemas da engenharia de software [Cui and Paige 2012]. A SysML pode adaptar a especificação de requisitos, independentemente do nível de detalhe, permitindo ao engenheiro de software detalhar requisitos em nível de usuário, como também pode ser usada para modelar componentes da estrutura interna de um software, o que fortalece sua aplicabilidade em uma ampla gama de projetos [Soares et al. 2011][Hampson 2015].

Desta forma, na hipótese de que a SysML possibilita um melhor entendimento aos engenheiros responsáveis sobre os requisitos do software, este trabalho propõe a criação de um processo para elicitar e documentar requisitos em nível de usuário utilizando a SysML para uso ao longo do ciclo de vida do desenvolvimento de um software. O processo foi desenvolvido em conjunto e aplicado em uma instituição pública por meio de uma pesquisa-ação e teve sua eficácia avaliada por meio de análise qualitativa.

A pesquisa-ação foi realizada em uma Universidade Federal do Brasil, especificamente em seu Núcleo de Tecnologia da Informação que é responsável por toda política e administração de Tecnologias da Informação (TI). Os projetos de desenvolvimento de software realizados neste ambiente específico apresentam os problemas relacionados à documentação de requisitos citados anteriormente, o que motivou o convite para realização deste estudo nesta instituição e o uso da metodologia de pesquisa-ação pela necessidade de realizar uma intervenção para melhoria de um problema específico.

O estudo possibilitou a integração entre a academia e uma instituição pública na solução de um problema real. Os resultados obtidos, mediante uma análise qualitativa, sugerem que tanto o processo proposto e aplicado quanto a linguagem SysML possibilitaram a solução dos problemas encontrados.

O texto deste artigo está organizado em seis seções. Na Seção 2 são apresentados trabalhos relacionados para os dois temas principais deste estudo: Pesquisa-ação na Engenharia Software e Documentação de Requisitos em Nível de Usuário Utilizando SysML. Na Seção 3 é descrita a metodologia utilizada, objetivo e as atividades e métodos utilizados no estudo. Na Seção 4 são apresentados o desenvolvimento do estudo da pesquisaação. O planejamento da pesquisa-ação é apresentado no item 4.1. Cada um dos 3 ciclos são apresentados respectivamente nas Seções de 4.2 a 4.4. Na Seção 5 são apresentados os métodos utilizados para avaliação do processo, a execução da avaliação, e a análise e interpretação dos dados obtidos. Por fim, na Seção 6 é apresentada a conclusão referente ao trabalho, as limitações e as principais contribuições do estudo.

\section{Trabalhos Relacionados}

Nesta seção são apresentados trabalhos relacionados a este estudo, identificados por meio de uma revisão da literatura acerca dos temas relacionados. Para esta revisão as buscas foram restritas aos últimos dez anos com o intuito de encontrar trabalhos re- 
centes no contexto da pesquisa-ação. Foram utilizadas quatro bases de conhecimento digitais, IEEE, Scopus, ScienceDirect e ACM. São apresentados estudos relacionados à utilização da metodologia da pesquisa-ação em Engenharia de Software e estudos relacionados ao contexto da documentação de requisitos em nível de usuário utilizando a SysML. Esta revisão da literatura foi realizada após a definição do problema identificado para a instituição pública participante do estudo.

\subsection{Pesquisa-ação na Engenharia de Software}

Pesquisa-ação é um tipo de pesquisa com base empírica que é concebida e realizada em estreita associação com uma ação ou com a resolução de um problema no qual os pesquisadores e os participantes representativos da situação, ou do problema, estão envolvidos de modo participativo [Thiollent 2011]. A pesquisa-ação está comprometida com a produção de novos conhecimentos por meio da busca de soluções ou melhorias para situações de problemas práticos [Elden and Chisholm 1993][Petersen et al. 2014]. Segundo Tripp [Tripp 2005], a pesquisa-ação utiliza-se de técnicas de pesquisa consagradas para informar a ação que se decide tomar para melhorar a prática.

No estudo realizado por Santos e Travassos [Dos Santos and Travassos 2011], os autores investigaram estudos relacionados à utilização da pesquisa-ação na Engenharia de Software por meio de uma revisão da literatura. Os autores identificaram 21 estudos entre os anos 1999 e 2010, sendo 6 deles voltados para implantação ou melhoria em processos de Engenharia de Software e 3 deles no contexto da Engenharia de Requisitos. Os autores também realizaram um estudo de pesquisa-ação para avaliação de um processo para refatoração de código fonte em um projeto de software de uma organização sem fins lucrativos voltada para TI em uma universidade federal do Brasil. Os autores descrevem de forma sistemática a avaliação realizada por meio de um estudo experimental, porém não fica claro no estudo a quantidade de ciclos de intervenção realizados.

Petersen et al. [Petersen et al. 2014] relatam os resultados da realização de dois estudos de pesquisa-ação em colaboração com a indústria. Em ambos os casos a pesquisaação necessitou de refinamentos nas intervenções realizadas em cada ciclo. Segundo os autores, um fator importante e considerado essencial foi a colaboração dos participantes nesse processo de refinamento. No estudo os autores salientam a necessidade de vários ciclos de intervenção até a obtenção de um resultado satisfatório, e sugerem a pesquisa-ação como um método capaz de obter resultados em uma possível colaboração entre academia e indústria.

No estudo realizado por Ramasubbu [Ramasubbu 2014], o autor relata a realização de um estudo de pesquisa-ação com foco na implementação de um processo de melhoria contínua do desenvolvimento de software de uma empresa multinacional. $\mathrm{O}$ autor descreve no estudo as intervenções e os ciclos de pesquisa-ação realizados durante um período de cinco anos em colaboração com a empresa, o que resultou em um processo personalizado que atendeu às necessidades sociais e técnicas das equipes da empresa. Os dois ciclos de pesquisa-ação realizados levaram cerca de dois anos de duração cada, com participação in loco do autor na empresa por aproximadamente dezoito meses. O autor relata que após realização da intervenção a empresa obteve melhorias com o desempenho na gestão de projetos, melhor controle das atividades dos projetos e melhor controle 
de recursos humanos relacionados aos projetos de software. O autor destaca como fator importante no sucesso da intervenção o envolvimento da alta gestão da empresa.

Oliveira et al. [Oliveira et al. 2015] sugerem a adaptação de um framework para gerenciamento de dívida técnica com o framework ágil Scrum. O estudo levou cerca de um ano e foram realizados três ciclos de pesquisa-ação. Os autores relatam que mesmo realizando três ciclos de pesquisa-ação e obtendo importante feedback prático, o estudo ainda não é conclusivo pois necessitam realizar mais ciclos para atender e avaliar as mudanças propostas no contexto dos participantes.

No estudo realizado por Sousa et al. [de Sousa et al. 2016], os autores utilizaram a pesquisa-ação para implantação de um processo para gestão de demandas de desenvolvimento ágil em uma fábrica de software de uma instituição federal do Brasil. O estudo levou cerca de um ano de duração e foi realizado por meio de dois ciclos de pesquisa-ação utilizando dois projetos piloto. Os projetos foram avaliados com o auxílio da abordagem GQM. Os autores relatam que a transferência gradual de conhecimento realizada por meio de cada ciclo de pesquisa-ação permitiu a implantação do processo com sucesso. Outro ponto positivo destacado foi a realização de treinamentos em cada ciclo para sanar dificuldades de capacitação encontradas durante a realização do estudo.

Embora poucos estudos utilizando a metodologia da pesquisa-ação em Engenharia de Software sejam realizados, os resultados dos estudos apresentados sugerem que uma pesquisa-ação realizada de forma sistemática pode trazer resultados positivos na parceria entre academia e indústria. Os pontos fortes destacados, como o envolvimento dos participantes e o apoio da gestão da empresa ou organização, são fatores que possibilitam ações de intervenção mais objetivas, inclusive com possibilidade de enriquecimento técnico e teórico dos participantes representantes da empresa ou instituição. Outro ponto relevante é o tempo de duração de cada estudo e a quantidade de ciclos necessários para alcançar os objetivos, que sugere que a pesquisa-ação necessita de um tempo considerável para sua realização no contexto da Engenharia de Software.

\subsection{Documentação de Requisitos em Nível de Usuário Utilizando SysML}

A SysML é uma linguagem gráfica de modelagem que pode ser utilizada na Engenharia de Software para modelagem de sistemas complexos [Friedenthal et al. 2008]. A SysML é uma extenção da UML e pode ser utilizada para representação de requisitos em nível de usuário por meio do diagrama de Requisitos e da Tabela de Requisitos [SysML 2015]. O diagrama de Requisitos da SysML ajuda na organização dos requisitos e também mostra os vários tipos de relações entre diferentes requisitos. O diagrama é útil para padronizar a maneira de especificar requisitos por meio de uma semântica previamente definida [Soares and Vrancken 2008]. A Tabela de Requisitos da SysML é usada para representar requisitos, suas propriedades e seus relacionamentos [SysML 2015]. A Tabela de Requisitos inclui os requisitos em cada linha, com seus atributos representados em suas colunas. Os relacionamentos entre requisitos e outros objetos também podem ser representados em uma tabela usando um estilo de matriz, que nesta perspectiva deve incluir os nomes dos elementos relacionados, os tipos de requisitos e o tipo de dependência entre os requisitos [SysML 2015]. 
Soares e Cioquetta [Soares and Cioquetta 2012] realizaram uma análise acerca dos métodos e linguagens utilizados para a documentação de requisitos em nível de usuário. Os resultados, por meio de uma visão das características dos métodos e linguagens, facilitam a escolha do engenheiro de software entre qual utilizar baseado no contexto do projeto a ser desenvolvido, como também identificar possibilidades de novos estudos acerca dos métodos e linguagens abordados. Os autores destacam que dois ou mais métodos podem ser utilizados em combinação para alcançar um melhor resultado. No estudo, a SysML destacou-se como linguagem que atende a um maior conjunto de critérios específicos para Engenharia de Requisitos, como a rastreabilidade entre requisitos, identificação dos tipos de requisitos, facilidade de interpretação pelos envolvidos, definição de prioridade e representação gráfica dos requisitos, em relação a linguagem natural estruturada, tabelas de decisão, viewpoints e casos de uso.

No estudo de Scanniello et al. [Scanniello et al. 2014], os autores investigaram, por meio de dois experimentos, se os diagramas de Requisitos da SysML oferecem benefícios adicionais em comparação com os diagramas de Casos de Uso da UML, em relação à facilidade de interpretação e documentação de requisitos em nível de usuário. Segundo os autores, os resultados sugerem que o uso do diagrama de Requisitos melhora a compreensão dos documentos sem afetar o tempo gasto para realização da tarefa pelos engenheiros de software.

Chang et al. [Chang et al. 2014] utilizaram um template para elicitação de requisitos e a SysML para documentar requisitos em nível de usuário, e a partir do diagrama de Requisitos gerar outros diagramas de acordo com as regras de transformação definidas pela ATLAS Transformation Language (ATL)[Jouault and Kurtev 2005]. O número de campos definidos para o template de requisitos, para atender a quantidade de dados necessários para criação dos diagramas, pode aumentar a dificuldade de atualização e manutenção dos requisitos, e consequentemente pode tornar esses artefatos obsoletos em um menor número de iterações. O template proposto por Chang et al.[Chang et al. 2014] possui uma grande quantidade de atributos, devido a necessidade de informações suficientes para geração dos diagramas de Atividade e Casos de Uso a partir do diagrama de Requisitos gerado com a utilização do template. Porém, em projetos em que as mudanças nos requisitos são frequentes isso pode tornar-se um problema devido às constantes atualizações necessárias na documentação de requisitos.

No estudo realizado por Muşat et al.[Muşat et al. 2016], os autores utilizaram a SysML para organizar os requisitos e para especificar, em alto nível, a estrutura e a interação entre componentes do software. Os autores sugerem que a representação baseada em diagrama de Requisitos permite melhor organização, processamento e classificação dos requisitos, em comparação com representações clássicas, como textos em linguagem natural. Os autores salientam que ao criar um modelo semi-formal, as ambiguidades são reconhecidas mais facilmente e evitadas em comparação com a linguagem natural. Porém, é preciso melhorar a compreensão dos requisitos e adicionar formalidades para simplificar a verificação dos requisitos e derivação dos mesmos em casos de teste. Em outro estudo, Amyot et al.[Amyot et al. 2016] realizaram uma investigação preliminar entre diferentes formas de combinar SysML com a URN (User Requirements Notation)[Amyot and Mussbacher 2011]. O estudo sugere que a SysML e a URN são 
complementares. Os autores confirmam os benefícios do diagrama de requisitos quanto a compreensão dos requisitos e destacam que as tabelas possuem melhor escalabilidade do que a representação em diagramas, especialmente quando se trata de um grande número de requisitos e relacionamentos. Segundo os autores, a SysML é mais simples que a UML pois possui menor número de diagramas, oferece conceitos e semânticas mais precisos e oferece melhor suporte para atividades da Engenharia de Requisitos.

Os estudos realizados por Muşat et al.[Muşat et al. 2016] e Amyot et al.[Amyot et al. 2016] relatam o uso da SysML e sua aplicação em diversos tipos de projetos. Os estudos também sugerem que existe uma facilidade para aplicação da SysML na indústria devido seus diagramas serem de fácil compreensão e a possibilidade de utilizar a SysML para complementar uma documentação de requisitos em nível de usuário.

\section{Metodologia}

Este trabalho caracteriza-se como uma pesquisa de natureza aplicada e possui uma abordagem qualitativa. Como instrumento de pesquisa foi realizada uma pesquisa-ação. A pesquisa-ação foi realizada em uma Instituição Federal de Ensino Superior do Brasil, mais precisamente em seu Núcleo de Tecnologia da Informação (NTI) que é responsável pela manutenção dos Sistemas Integrados de Gestão. Atualmente, os Analistas de Sistemas desta Instituição vem enfrentando dificuldade para elicitar, documentar e manter os requisitos de software e consequentemente também encontram dificuldades nas atividades de rastreabilidade e validação.

\subsection{Objetivo}

O principal objetivo desta pesquisa é propor e aplicar um processo para elicitar e documentar requisitos em nível de usuário utilizando a SysML por meio de uma pesquisaação em uma instituição pública, para uso ao longo do ciclo de vida de desenvolvimento do software.

\subsection{Atividades e Métodos utilizados neste Estudo de Pesquisa-ação}

Para execução da pesquisa-ação, seguindo as orientações propostas por Mckay e Marshall [McKay and Marshall 2001], após a definição do problema foi realizada uma revisão da literatura com o objetivo de situar o objeto de estudo de acordo com o estado da arte, relacionando-o ao referencial teórico [Kitchenham 2004]. Em seguida, após um planejamento em conjunto com os participantes, foram iniciados os ciclos da pesquisaação.

Três ciclos de pesquisa-ação foram definidos para este estudo. Foram considerados ciclos preliminares o primeiro e segundo ciclo e considerado como ciclo de intervenção o terceiro ciclo. Chamamos de ciclos preliminares os que obtiveram resultados parciais em relação ao objetivo final do estudo e chamamos de ciclo de intervenção aquele que consideramos como resultado uma resolução mais abrangente do problema. Para o primeiro ciclo foi definido como objetivo a proposta de um template para elicitação e documentação de requisitos em nível de usuário; para um segundo ciclo a proposta de um processo para elicitar e documentar requisitos em nível de usuário foi estabelecida como objetivo; e para o terceiro ciclo foram realizadas as atividades de execução e avaliação do processo proposto. 
Foi realizado no início de cada ciclo de pesquisa-ação um workshop para interação, desenvolvimento e discussão das atividades realizadas em cada ciclo. Um workshop permite que os pesquisadores e participantes realizem uma reunião focada nos objetivos e permite envolver os participantes de maneira que os mesmos se sintam proprietários dos resultados [CBOK 2013].

Ao final de cada ciclo foram realizadas reuniões de feedback por meio de entrevistas semi estruturadas com os participantes da pesquisa-ação para analisar os resultados e definir ações para o próximo ciclo de pesquisa-ação[Latum et al. 1998]. Com o encerramento do ciclo e após a reunião de feedback, iniciou-se um novo ciclo de pesquisa-ação. A avaliação final do processo ocorreu por meio da aplicação de um questionário e uma entrevista semi estruturada. A abordagem GQM (Goal, Question, Metric) foi utilizada para auxiliar na definição das questões e métricas de avaliação [Basili and Weiss 1984]. A etapa de coleta dos dados por meio do questionário e entrevista foi realizada de forma individual no último ciclo de pesquisa-ação. Após encerramento da avaliação final a pesquisa-ação foi encerrada.

\section{Desenvolvimento do Estudo de Pesquisa-ação}

\subsection{Planejamento da pesquisa-ação}

Em reunião realizada entre Analistas de Sistemas, Coordenador de Sistemas, Diretor do NTI e os pesquisadores deste estudo, foi identificado que o NTI não possui um processo de Engenharia de Requisitos, atividade que tem sido executada Ad-hoc pelos Analistas e programadores envolvidos em cada projeto. Considerando este cenário, um processo para elicitação e documentação de requisitos em nível de usuário foi proposto, aplicado e avaliado, uma vez que, como atividades iniciais em um projeto de desenvolvimento de software, é de suma importância que sejam executadas com efetividade para que as fases posteriores transcorram com o menor índice possível de defeitos. O NTI disponibilizou uma equipe de doze Analistas de Sistemas para participação neste estudo.

Tabela 1. Caracterização dos participantes

\begin{tabular}{|l|c|c|c|}
\hline Participante & Idade & $\begin{array}{l}\text { Experiência em } \\
\text { desenvolvimento } \\
\text { de software(anos) }\end{array}$ & $\begin{array}{l}\text { Experiência } \\
\text { no NTI (anos) }\end{array}$ \\
\hline P1 & 26 & 04 & 02 \\
\hline P2 & 25 & 02 & 02 \\
\hline P3 & 24 & 06 & 02 \\
\hline P4 & 34 & 12 & 12 \\
\hline P5 & 32 & 10 & 10 \\
\hline P6 & 26 & 06 & 06 \\
\hline P7 & 27 & 04 & 04 \\
\hline P8 & 33 & 03 & 03 \\
\hline P9 & 24 & 04 & 04 \\
\hline P10 & 25 & 02 & 01 \\
\hline P11 & 25 & 03 & 03 \\
\hline P12 & 30 & 10 & 05 \\
\hline
\end{tabular}

O processo de seleção dos participantes ocorreu por conveniência. Os participan- 
tes deste estudo foram selecionados a partir de cinco projetos em andamento no NTI, no qual as etapas de elicitação e documentação de requisitos já foram realizadas. Os participantes escolhidos participaram das atividades realizadas nos ciclos de pesquisa-ação. Uma lista com os participantes e suas características está disposta na Tabela 1.

Entre os selecionados, apenas dois participantes (16,7\%) ainda não possuem nível superior completo. Três participantes $(25,0 \%)$ possuem 10 anos ou mais de experiência em desenvolvimento de software, dois participantes (16,7\%) possuem experiência entre 05 e 09 anos e sete participantes $(58,3 \%)$ até 04 anos de experiência, incluindo os não graduados.

Com relação ao cargo dos participantes, todos exercem a função de Analista de Sistemas, todos os profissionais participam tanto das atividades de análise quanto de programação. Tais profissionais contribuem tanto com a elicitação e documentação de requisitos quanto com o design e codificação do software. Todos os participantes fazem parte do quadro funcional da instituição participante.

O planejamento inicial foi realizado após a revisão da literatura. Embora seja realizado para cada ciclo de pesquisa-ação um planejamento específico, é permitido ao pesquisador fazer ajustes adequadamente durante o processo de aprendizagem e implementação de melhorias, devido às características semelhantes a um processo de melhoria contínua da pesquisa-ação [Petersen et al. 2014]. Seguindo esta afirmação, os ciclos de pesquisaação seguiram as atividades de planejamento, implementação e análise do ciclo, conforme sugerido em [McKay and Marshall 2001].

\subsection{Primeiro ciclo de pesquisa-ação}

Neste primeiro ciclo foi realizado um workshop para alinhamento com os participantes da pesquisa-ação em relação aos métodos, abordagens, técnicas e tecnologias utilizadas, como também a definição das metas institucionais observadas neste estudo. Também neste primeiro ciclo foi proposto o template para requisitos em nível de usuário, que foi apresentado pelos pesquisadores e será avaliado pelos participantes, por meio de entrevista semi-estruturada, para que os atributos necessários para documentação desses requisitos, no contexto desta pesquisa-ação, sejam validados.

O primeiro workshop foi realizado no mês de dezembro de 2017 com a presença de todos os participantes. De início, foram detalhados aos participantes a metodologia da pesquisa-ação e as atividades que deveriam ser realizadas em cada ciclo de pesquisaação para este projeto. Também foi destacado o número de encontros presenciais, a priori duas reuniões a cada ciclo, sendo uma reunião geral em formato de workshop e outra de feedback.

A SysML foi apresentada em um contexto geral e foi detalhado o seu uso em relação aos requisitos de software. A tabela de Requisitos e o diagrama de Requisitos foram apresentados para os participantes, sendo destacadas suas principais características e sua aplicabilidade no contexto da instituição. Participaram da reunião como Instrutor um dos Pesquisadores deste estudo e como ouvintes os participantes representantes da instituição nesta pesquisa-ação.

Por fim, foi apresentado aos participantes o template proposto e foram detalhados

iSys: Revista Brasileira de Sistemas de Informação (iSys: Brazilian Journal of Information Systems) 
cada um dos seus atributos. Também foi definido que a reunião de feedback deste ciclo seria realizada na forma de entrevista individual para avaliação dos atributos do template apresentado. Os resultados da entrevista estão descritos na Seção 4.2.2.

\subsubsection{Proposta de Template para Documentação de Requisitos em Nível de Usuário}

O objetivo é definir um template estruturado que auxilie o Analista de Sistemas na elicitação e documentação de requisitos capaz de fornecer as informações necessárias para a codificação e testes do software pela equipe do NTI, que possibilite o uso da SysML por meio do seu Diagrama de Requisitos e Tabela de Requisitos.

O template foi aplicado na elicitação dos requisitos em complemento a técnicas de elicitação convencionais utilizadas pelos Analistas de Sistemas do NTI. As informações para preenchimento do template podem ser identificadas e coletadas por meio de entrevistas, brainstorm, questionários, análise de processos de negócio, observação em campo, análise de documentos de valor legal como Leis, Resoluções e Portarias e outras técnicas que possam ser necessárias para condução do projeto. A SysML foi utilizada para facilitar a interpretação e visualização dos requisitos criados. O Diagrama de Requisitos e a Tabela de Requisitos foram gerados a partir dos atributos registrados.

Tabela 2. Template proposto para documentação de requisitos

\begin{tabular}{|c|c|c|}
\hline Atributo & Tipo de dado & Descrição/Motivação \\
\hline ID $(*)$ & Numérico & Baseado na SysML (ID). \\
\hline Nome $(*)$ & Texto & Baseado na SysML (Text). \\
\hline Descrição & Texto & Descrição textual detalhada do requisito e regra de negócio. \\
\hline Data $(*)$ & Data & Registro de data de abertura e data de modificação. \\
\hline Status $(*)$ & Texto & $\begin{array}{l}\text { Status do requisito (Novo, Aprovado, Cancelado, } \\
\text { Finalizado). }\end{array}$ \\
\hline Participantes externos & Texto & Lista de envolvidos na definição e validação do requisito. \\
\hline $\begin{array}{l}\text { Funcional ou } \\
\text { Não Funcional }(*)\end{array}$ & Texto & $\begin{array}{l}\text { Informar se um Requisito é do tipo Funcional ou Não } \\
\text { Funcional. }\end{array}$ \\
\hline Prioridade $(*)$ & Texto & $\begin{array}{l}\text { Definição do grau de importância do Requisito } \\
\text { (Alto, Médio, Baixo). }\end{array}$ \\
\hline Documentação Legal & Documentos Externos & $\begin{array}{l}\text { Campo para anexar documentos. Motivado pela } \\
\text { necessidade de relacionar um requisito a uma norma ou } \\
\text { dispositivos de Lei. }\end{array}$ \\
\hline $\begin{array}{l}\text { Relação com outros } \\
\text { módulos do sistema }\end{array}$ & Texto & $\begin{array}{l}\text { Registro de dependências entre módulos ou sistemas } \\
\text { conhecidas, pelos participantes e Analistas. Motivado } \\
\text { pela dificuldade atual de rastreabilidade de impacto de } \\
\text { mudanças entre funcionalidades,módulos e sistemas. }\end{array}$ \\
\hline $\begin{array}{l}\text { Relacionamento } \\
\text { entre Requisitos }\end{array}$ & $\begin{array}{l}\text { ID Requisito/ } \\
\text { Tipo de Relação }\end{array}$ & $\begin{array}{l}\text { Tipo de Relacionamento baseado na SysML. } \\
\text { (Containment, Derive, Satisfy, Verify, Refine, Trace, Copy) }\end{array}$ \\
\hline
\end{tabular}

No início deste estudo, os requisitos em nível de usuário eram documentados pela equipe do NTI utilizando um documento com uma lista de requisitos com apenas dois atributos, um atributo de identificador único (ID) e uma descrição em linguagem natural 
do requisito. Para criação do template, foi analisada a conformidade do template proposto, por meio dos seus atributos, em relação às características individuais dos requisitos segundo a norma ISO/IEC/IEEE 29148:2011 [ISO 2011].

Os atributos propostos para compor o template de requisitos em nível de usuário para o NTI estão descritos na Tabela 2 em sua versão final, após a validação dos participantes. A coluna Atributo descreve o nome do atributo proposto para ser utilizado no template, a coluna Tipo de Dado descreve o tipo específico do dado a ser armazenado e a coluna Descrição/Motivação descreve a necessidade de utilização deste atributo e sua função no template. Os atributos marcados com o símbolo de um (*) referem-se aos campos obrigatórios necessários para uma documentação mínima do requisito.

\subsubsection{Análise Qualitativa dos Atributos Propostos para o Template}

Em entrevista semi-estruturada realizada no mês de dezembro de 2017, todos os 12 participantes da pesquisa-ação, representantes da instituição, foram entrevistados individualmente com intuito de coletar informações referentes aos atributos propostos no template. Cada entrevistado teve um tempo de dez minutos para responder as questões. As respostas foram coletadas pelo entrevistador por meio de anotações individuais para cada entrevistado. A Tabela 1 apresenta o perfil dos participantes.

Durante a entrevista, foram realizadas as seguintes perguntas:

1 Algum atributo do template proposto pode ser considerado desnecessário para utilização?

2 Algum atributo pode ser considerado necessário incluir no template? Qual a motivação para usar este atributo?

3 Existe algum documento que seja gerado a partir dos requisitos? Qual sua finalidade?

Com relação à primeira pergunta, sobre algum atributo que é desnecessário no template, $100 \%$ dos entrevistados não identificaram nenhum atributo desnecessário. Os Analistas de Sistemas destacaram a importância do atributo "Documentação legal" que muitas vezes é o principal motivador de novos requisitos e não é atualmente utilizado na documentação de requisitos. Outros atributos destacados na entrevista foram os "Participantes externos" e "Relação com outros módulos do sistema". O primeiro lista os envolvidos com a definição daquele requisito, e o segundo registra os possíveis relacionamentos com outros módulos baseados na experiência dos envolvidos que segundo os participantes ajuda a determinar o domínio e o impacto daquele requisito. Outro ponto importante foi a declaração por parte dos entrevistados sobre uma expectativa por uma visão dos relacionamentos dos requisitos por meio de um diagrama, reflexo do que foi apresentado no Workshop por meio do diagrama de Requisitos da SysML.

Com relação à segunda pergunta, os entrevistados solicitaram, em sua totalidade, que um campo para identificação do tipo funcional ou não funcional do requisito fosse incluído. Outro atributo solicitado e que foi incluído foi o "Nome", segundo a maioria dos participantes, inclusive os mais experientes, os atributos "ID" e "Nome" correspondem no 
template aos campos básicos sugeridos pela SysML (ID e Text) e o campo "Descrição" será um campo não obrigatório para descrever a justificativa e detalhes da regra de negócio daquele requisito, esta informação é fornecida pelo usuário demandante ou identificado na elicitação pelo Analista. Outro campo sugerido pela maioria dos participantes foi um campo para determinar o "grau de importância" do requisito, neste caso foi adicionado o atributo "prioridade" para atender essa necessidade.

Um ponto que merece destaque durante a coleta de respostas da segunda pergunta foi a dificuldade dos participantes em relação a diferença entre requisitos em nível de usuário e requisitos em nível de sistema, mesmo entre os mais experientes. Em alguns casos os participantes sugeriram atributos com um nível de detalhe técnico ainda não abordado nesta fase do projeto, por exemplo detalhes das tabelas no banco de dados e referências a classes do código fonte, estes atributos foram rejeitados. Outros atributos sugeridos e que também foram rejeitados tratavam-se de informações referentes a gestão do projeto como dados de reuniões entre os Analistas e usuários e dados referente a métricas como pontos de função do projeto.

Com relação à terceira e última pergunta, todos os entrevistados indicaram, como documento gerado pelos Analistas de Sistemas a partir dos requisitos em nível de usuário, uma lista contendo os requisitos com os dados como o ID, descrição do requisito, data e responsáveis pela aprovação destes requisitos. Este artefato é assinado pelos Analistas de Sistemas responsáveis pela criação do software e pelo usuário demandante. Diante desta afirmação, os participantes confirmaram que os dados necessários para criação do documento estão incluídos no template, atendendo esta necessidade interna. A forma como será gerada e assinada essa lista de requisitos será tratada no segundo ciclo de pesquisa-ação.

Por fim, com as alterações realizadas, o template foi aprovado por unanimidade e utilizado no processo para documentação de requisitos a ser proposto. O template final está representado na Tabela 2 por meio dos seus atributos.

Com a definição e aprovação dos atributos do template pelos participantes, o primeiro ciclo de pesquisa-ação foi encerrado. A participação ativa dos representantes da instituição ficou destacada como ponto positivo. Como ponto negativo pode-se destacar o conhecimento relacionado a Requisitos de Software demonstrado pelos participantes, inclusive quanto aos limites entre requisitos em nível de usuário e requisitos em nível de sistema. Desta forma, foi proposto um novo workshop para o segundo ciclo de pesquisaação com o tema Requisitos de Software para alinhamento entre os participantes.

\subsection{Segundo Ciclo de Pesquisa-ação}

Para o segundo ciclo de pesquisa-ação, o mesmo planejamento do primeiro ciclo foi mantido, com uma reunião em formato de workshop e reuniões de feedback por meio de entrevistas individuais.

Este segundo ciclo caracteriza-se pela proposta do processo para realização da elicitação e documentação de Requisitos em nível de usuário utilizando o template proposto no primeiro ciclo, como também a validação do processo por meio do feedback dos participantes acerca das atividades e artefatos propostos. Porém, sua execução será rea- 
lizada no próximo ciclo. Neste próximo ciclo tanto o template quanto o processo e seus artefatos foram avaliados de forma sistemática.

Mantendo o planejado, um workshop foi realizado para rever os resultados do primeiro ciclo, também foi realizada uma apresentação sobre fundamentos em Engenharia de Requisitos com foco em requisitos em nível de usuário, com objetivo de revisar os conhecimentos na área para os participantes da pesquisa-ação, para atender a demanda gerada a partir das entrevistas realizadas no primeiro ciclo.

Também foi proposto um processo para Elicitação e Documentação de Requisitos em nível de usuário por meio de uma apresentação para os participantes desta pesquisaação. Em sequência, foi realizada uma entrevista semi-estruturada e individual com os participantes para validar o processo, incluindo suas atividades e artefatos. Esta entrevista foi realizada em uma etapa posterior, com intervalo de uma semana, para que os participantes pudessem analisar as atividades e artefatos gerados no processo proposto.

Neste segundo ciclo, por solicitação dos participantes e da coordenação do NTI, o workshop foi realizado em três reuniões, devido a manutenção das atividades realizadas no NTI naquele período pelos participantes o que poderia prejudicar o andamento dos projetos. As reuniões foram realizadas no mês de março de 2018. A primeira reunião teve a participação de seis Analistas de Sistemas e a segunda e terceira de três Analistas de Sistemas em cada. Embora realizadas em dias diferentes, as reuniões do workshop seguiram o mesmo roteiro conforme descrito a seguir.

A reunião foi iniciada com uma revisão dos objetivos da pesquisa-ação e com os resultados do primeiro ciclo. Em seguida, de forma a mitigar uma das ameaças identificadas na conclusão do primeiro ciclo, um treinamento em requisitos de software com foco na diferença entre requisitos em nivel de usuário e em nível de sistema foi realizado.

Dando continuidade ao objetivo principal do segundo ciclo, que consiste na proposta do Processo para Engenharia de Requisitos baseado na SysML, foi apresentado o processo proposto e suas atividades e artefatos. Após a apresentação do processo, houve interação entre os participantes e os pesquisadores em uma breve discussão sobre as atividades e artefatos propostos. Essa discussão, realizada em forma de brainstorm, foi iniciada propositalmente pelo pesquisador condutor do workshop para estimular a contribuição dos participantes na definição do processo proposto. Essa atividade foi realizada nas três reuniões e durou cerca de 20 minutos na primeira reunião e cerca de 10 minutos nas outras duas reuniões. O foco foi sobre o entendimento da sequência das atividades e os artefatos gerados em cada etapa, com o objetivo de sanar possíveis dúvidas que pudessem comprometer a reunião de feedback planejada. Após encerramento da discussão, o material utilizado na apresentação e que descreve o processo proposto e suas atividades e artefatos foi disponibilizado para os participantes.

Por fim, a validação das atividades e artefatos propostos no processo foi realizada por meio de uma entrevista semi estruturada realizada individualmente após uma semana da realização de cada reunião. Os resultados da entrevista estão descritos na Seção 4.3.3. 


\subsubsection{Mapeamento do Processo Atual}

Propostas de mudanças em processos devem ser iniciadas com o entendimento do estado atual, ou seja, não se deve omitir ou simplesmente começar do zero como se a organização não tivesse algum passado [CBOK 2013]. Desta forma, foram identificados os participantes, as atividades e os artefatos do processo atual por meio da análise de projetos realizados anteriormente e com os dados coletados pelos pesquisadores durante as reuniões com os Analistas participantes e por meio da observação em campo após a autorização do estudo pela coordenação do NTI.

Como descrito pelos representantes da instituição no início deste estudo, as atividades foram descritas como realizadas de forma ad-hoc com algumas tarefas obrigatórias a serem executadas pelos Analistas de Sistemas.

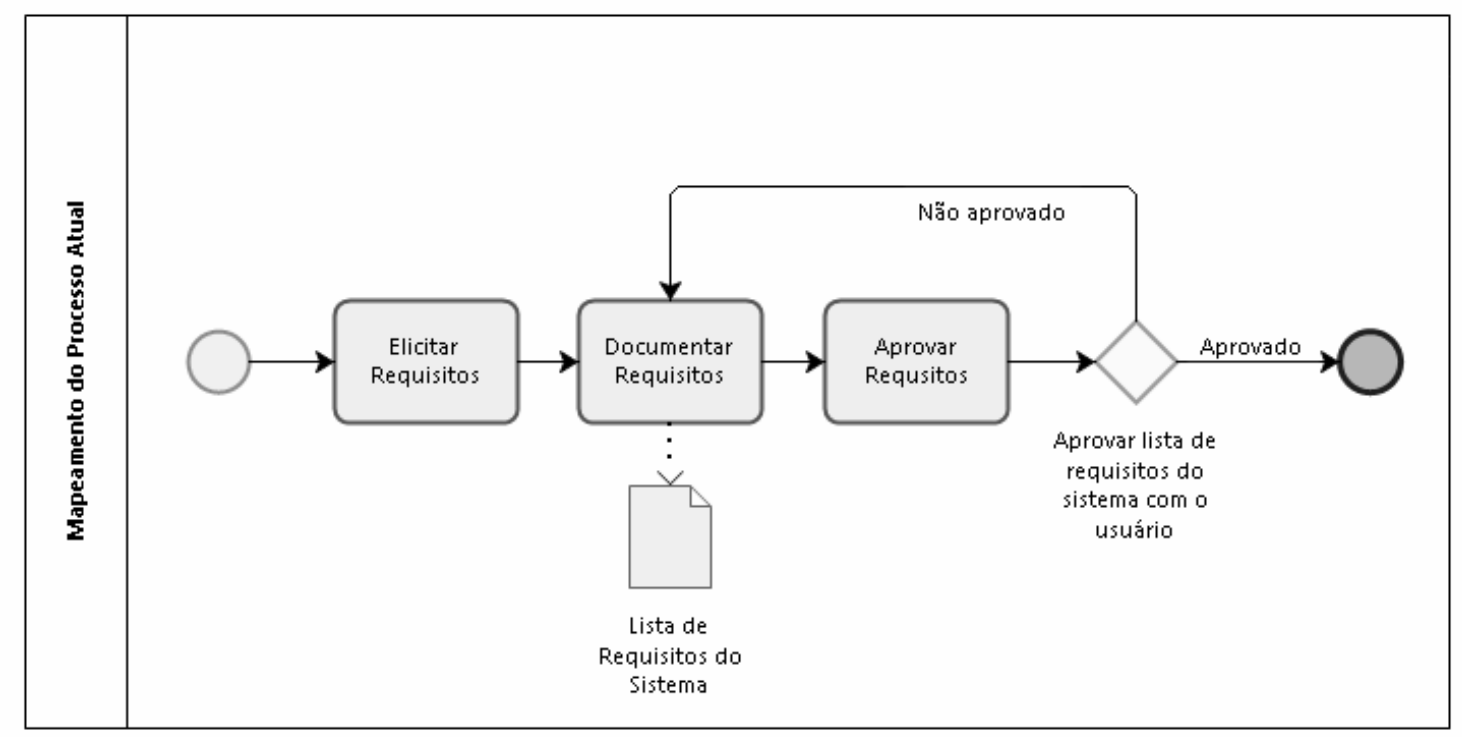

Figura 1. BPMN - Mapeamento do Processo Atual

A solicitação de demanda de um novo software é realizada pelo usuário demandante por meio de um questionário disponibilizado online. Após receber esta demanda, os Analistas de Sistemas emitem um parecer sobre o impacto e a possibilidade de realização do projeto que após autorização da coordenação de sistemas do NTI pode iniciar o projeto.

O mapeamento do processo atual foi validado pelos participantes do estudo.

A primeira atividade realizada para o processo é a Elicitação, iniciando assim o processo atual, que é realizado por meio de técnicas como entrevistas e brainstorm, escolhidas de acordo com as habilidades individuais de cada Analista de Sistemas e da necessidade do projeto.

A documentação é realizada com a descrição dos requisitos em um documento, uma tarefa considerada obrigatória pela coordenação de sistemas devido a necessidade de 
definir o escopo do projeto junto ao usuário demandante. Após a criação deste documento, uma reunião com os usuários é realizada para validação e aprovação dos requisitos, encerrando assim o processo. Com o encerramento, os Analistas de Sistemas prosseguem com as atividades como a criação de tarefas de codificação para os programadores, casos de teste e documentação do software.

\subsubsection{Processo para Elicitação e Documentação de Requisitos em Nível de Usuário}

O objetivo é definir um processo para elicitação e documentação de requisitos em nível de usuário, utilizando o template proposto no primeiro ciclo de pesquisa-ação, definindo suas atividades e artefatos, em concordância com os objetivos institucionais do Núcleo de Tecnologia da Informação da Universidade Federal de Sergipe.

Tabela 3. Papéis e Responsabilidades

\begin{tabular}{|l|l|}
\hline Papel & \multicolumn{1}{c|}{ Descrição } \\
\hline Analista de Sistemas & $\begin{array}{l}\text { Responsável técnico pela execução do processo de requisitos em } \\
\text { nível de usuário, inclusive por coletar, documentar e analisar os } \\
\text { requisitos durante o processo. }\end{array}$ \\
\hline Cliente & $\begin{array}{l}\text { Usuário demandante que é responsável pela solicitação do } \\
\text { sistema, definição e aprovação dos requisitos. }\end{array}$ \\
\hline
\end{tabular}

Neste estudo, o processo proposto contemplará as atividades necessárias para realização da elicitação, documentação, análise e validação dos requisitos em nível de usuário para os projetos de software do NTI.

Tabela 4. Descrição dos Subprocessos

\begin{tabular}{|l|l|}
\hline Nome do Subprocesso & \multicolumn{1}{c|}{ Descrição } \\
\hline Elicitar Requisitos & $\begin{array}{l}\text { Compreende as atividades relacionadas a identificação dos } \\
\text { stakeholders e as definições da regra de negócio do sistema em } \\
\text { requisitos de software. }\end{array}$ \\
\hline Documentar Requisitos & $\begin{array}{l}\text { Compreende as atividades relacionadas a documentação dos } \\
\text { requisitos, incluindo a geração de artefatos da SysML. }\end{array}$ \\
\hline Analisar Requisitos & $\begin{array}{l}\text { Compreende as atividades relacionadas a análise de conflitos entre } \\
\text { requisitos e priorização dos mesmos pelo seu grau de importância. }\end{array}$ \\
\hline Validar Requisitos & $\begin{array}{l}\text { Compreende as atividades relacionadas a validação dos requisitos } \\
\text { em conformidade com a norma ISO/IEC/IEEE 29148:2011, e } \\
\text { geração da lista de requisitos em nível de usuário definidas para o } \\
\text { sistema e aprovação dos requisitos pelo Cliente. }\end{array}$ \\
\hline
\end{tabular}

O processo é composto de quatro subprocessos: Elicitar Requisitos, Documentar Requisitos, Analisar Requisitos e Validar Requisitos. Dentro de cada subprocesso, existe um conjunto de atividades a serem realizadas para conclusão de cada tarefa. O processo sugerido é baseado na norma ISO/IEC/IEEE 29148:2011, observando as características propostas para um conjunto de requisitos. A execução do processo resultará em um conjunto de requisitos que servem de apoio a decisões arquiteturais, a rastreabilidade e a decomposição destes requisitos durante o ciclo de vida de desenvolvimento do 
software, colaborando com a definição da estrutura do sistema, e definição de um conjunto de artefatos mais detalhados [ISO 2011]. As características sugeridas pela norma ISO/IEC/IEEE 29148:2011 norteiam a definição das atividades e artefatos deste processo. Tais características ajudam na definição de um conjunto de requisitos em concordância com as características individuais e critérios de qualidade para cada Requisito.

Os papéis definidos para o processo estão dispostos na Tabela 3. A coluna papel apresenta o nome do papel e a coluna Descrição descreve a responsabilidade daquele papel durante o processo. São necessários dois papéis neste processo, o de Analista de Sistemas e o de Cliente. O papel Analista de Sistemas é o responsável e principal executor do processo. Outro papel é o Cliente que representa o usuário demandante e/ou detentor da regra de negócio do software, que embora não seja responsável pela execução de nenhuma atividade ou tarefa do processo, é fundamental a sua identificação uma vez que o mesmo é participante de atividades essenciais no processo.

Neste estudo foi utilizada a notação BPMN para modelagem do processo, justifica-se sua escolha por ser considerada uma notação de ampla aceitação na indústria [OMG 2011][Pillat et al. 2015]. Também pode-se justificar a escolha da BPMN devido ao domínio do uso da notação pelos Analistas de Sistemas do NTI. Para modelagem foi utilizada a ferramenta Bizagi Process Modeler em sua versão gratuita que dá suporte à notação BPMN [Bizagi 2018]. A Bizagi Process Modeler é uma ferramenta de uso comum entre os Analistas de Sistemas do NTI, inclusive os participantes deste estudo. Atualmente, a BPMN é considerada uma notação padrão e de ampla aceitação na indústria para modelagem de processos de negócio [Chinosi and Trombetta 2012][Leopold et al. 2016][Geiger et al. 2018].

Os subprocessos estão detalhados na Tabela 4, que contêm o nome e a descrição dos mesmos. As atividades de cada subprocesso estão documentadas por meio de uma tabela contendo as colunas Nome da Atividade e Detalhamento. A coluna Detalhamento contêm os dados referentes à descrição da atividade, os responsáveis e participantes de cada atividade, inclusive os artefatos gerados e as ferramentas utilizadas durante a execução da referida atividade.

O subprocesso Elicitar Requisitos, primeiro a ser executado, envolve as atividades de Identificação dos Stakeholders, Identificação dos Requisitos de Software e a Coleta dos Dados dos Requisitos, conforme o detalhamento das atividades representado na Tabela 5. 
Tabela 5. Atividades do Subprocesso Elicitar Requisitos

\begin{tabular}{|c|c|}
\hline Nome da Atividade & Detalhamento \\
\hline Identificar Stakeholders & $\begin{array}{l}\text { Descrição: Identificar os stakeholders que possuem conhecimento } \\
\text { da regra de negócio do software. } \\
\text { Responsáveis: Analista de Sistemas } \\
\text { Participantes: Analista de Sistemas e Cliente } \\
\text { Artefatos Gerados: Lista de Stakeholders }\end{array}$ \\
\hline Identificar Requisitos & $\begin{array}{l}\text { Descrição: Identificar os requisitos utilizando-se de técnicas } \\
\text { convencionais (entrevista, brainstorm e questionário). } \\
\text { Responsáveis: Analista de Sistemas } \\
\text { Participantes: Analista de Sistemas, Cliente e Stakeholders } \\
\text { Artefatos Gerados: Lista de Requisitos (Inicial) }\end{array}$ \\
\hline Coletar dados dos Requisitos & $\begin{array}{l}\text { Descrição: Coletar os dados necessários para documentação dos } \\
\text { requisitos identificados de acordo com o template. } \\
\text { Responsáveis: Analista de Sistemas } \\
\text { Participantes: Analista de Sistemas, Cliente e Stakeholders }\end{array}$ \\
\hline
\end{tabular}

$\mathrm{Na}$ atividade Identificar Stakeholders é gerada uma lista dos principais stakeholders para o projeto. Esta identificação é feita por meio da análise de documentos institucionais como o organograma da instituição, documentos que motivem a execução do projeto como leis ou portarias institucionais, pela indicação de novos stakeholders feita diretamente pelo usuário demandante ou responsável pela aprovação do projeto.

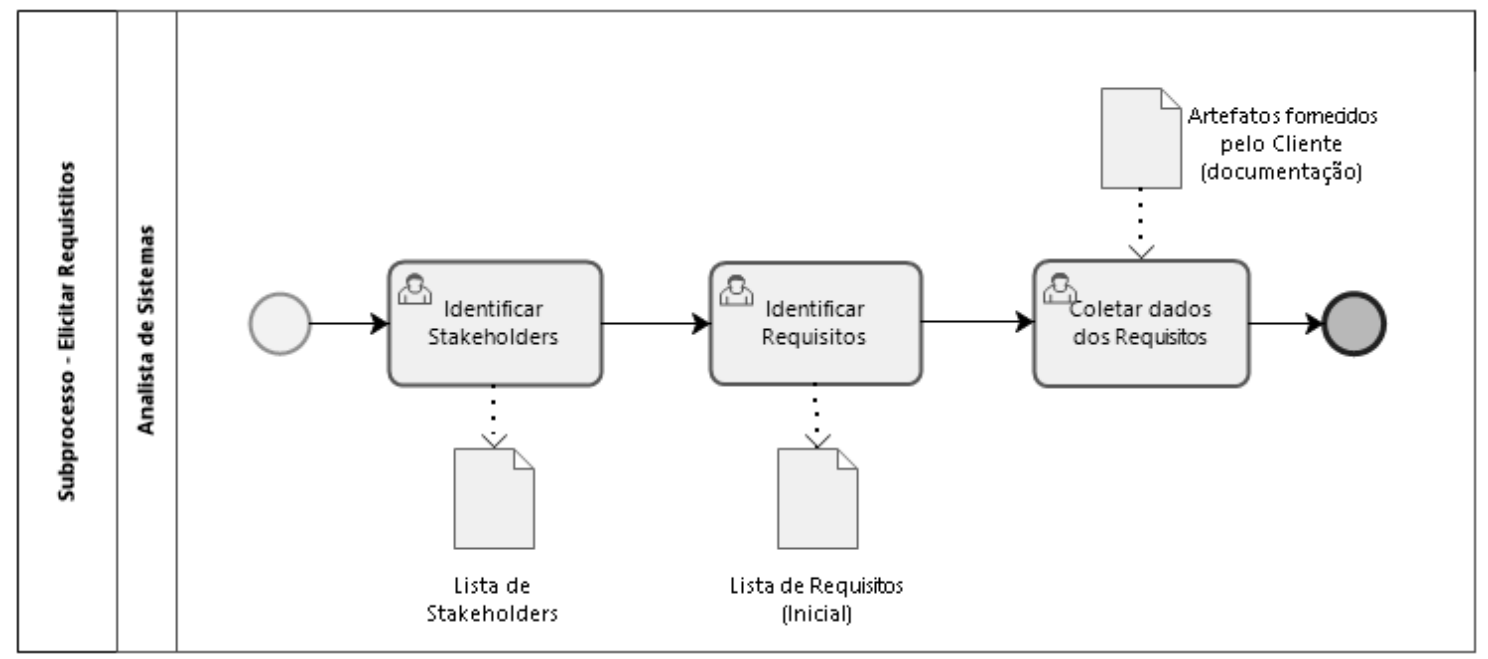

Figura 2. BPMN - Subprocesso Elicitar Requisitos

Para Identificar os Requisitos, os stakeholders responsáveis pela definição da regra de negócio são convocados para uma reunião, conduzida pelos Analistas de Sistemas. Nesta reunião são identificados os requisitos de forma primária, gerando como artefato uma lista inicial dos requisitos do software. Em seguida, a partir de cada requisito identificado, o Analista de Sistemas coleta os dados específicos para preenchimento do template para documentação de requisitos em nível de usuário com os stakeholders participantes. Esta atividade é descrita no processo como Coletar dados dos Requisitos. A atividade Coletar dados dos Requisitos não gera um artefato específico devido os dados coletados estarem documentados de forma bruta, feito por meio de anotações realizadas pelo 
Analista de Sistemas nas reuniões ou coleta de documentos que forneçam informações referente ao requisito, o que necessita uma análise posterior e gera a necessidade de revisão dos dados de cada requisito para realizar a documentação. A Figura 2 apresenta a modelagem do subprocesso Elicitar Requisitos. Após o encerramento dessas atividades é iniciado o subprocesso Documentar Requisitos.

De posse dos dados necessários para documentação dos requisitos, o Analista de Sistemas inicia o segundo subprocesso. As atividades para o subprocesso Documentar Requisitos resumem-se em registrar os dados dos requisitos elicitados e indicar os tipos de relacionamento entre requisitos baseados na SysML para geração da documentação baseada na SysML. O detalhamento destas atividades está representado na Tabela 6. A modelagem do subprocesso Documentar Requisitos está representada na Figura 3.

Tabela 6. Atividades do Subprocesso Documentar Requisitos

\begin{tabular}{|c|c|}
\hline Nome da Atividade & Detalhamento \\
\hline Registrar dados dos Requisitos & $\begin{array}{l}\text { Descrição: Registrar dados coletados na elicitação dos Requisitos } \\
\text { no template customizado na ferramenta. } \\
\text { Responsáveis: Analista de Sistemas } \\
\text { Participantes: Analista de Sistemas } \\
\text { Artefatos Gerados: Documento de Requisitos em nível de } \\
\text { usuário (Inicial) }\end{array}$ \\
\hline Indicar Relacionamento SysML & $\begin{array}{l}\text { Descrição: Indicar o tipo de relacionamento entre requisitos e } \\
\text { gerar artefatos da SysML. } \\
\text { Responsáveis: Analista de Sistemas } \\
\text { Participantes: Analista de Sistemas } \\
\text { Artefatos Gerados: Diagrama e Tabela de Requisitos (SysML) }\end{array}$ \\
\hline
\end{tabular}

Para documentar os requisitos elicitados, atividade denominada Registrar os dados dos Requisitos, será utilizada a ferramenta de gestão de tarefas Redmine, opensource, com acesso via web, de domínio dos desenvolvedores de software do NTI. Redmine é uma ferramenta utilizada para o gerenciamento de projetos, multi plataforma e com suporte para diversos tipos de bancos de dados [Redmine 2018]. A ferramenta permite que os requisitos sejam armazenados em banco de dados com possibilidade de geração de backup e fornece opções de customização de campos que facilitam a implementação e utilização do template proposto. A ferramenta dispensa avaliação por já ser utilizada há mais de 5 anos pelos Analistas de Sistemas do NTI para gerenciar suas tarefas de desenvolvimento, e ser de consenso entre os participantes deste estudo a sua eficácia para este contexto.

Para realização da atividade Indicar relacionamento SysML será utilizada uma ferramenta para auxiliar os Analistas de Sistemas na sua execução. Devido o NTI possuir uma restrição de orçamento para aquisição de ferramentas, tendo a maioria de suas ferramentas de trabalho open source ou versões grátis de ferramentas comerciais, o principal critério para escolha da ferramenta foi justamente a sua gratuidade. Outro ponto observado na escolha foi a necessidade de atender a notação usada pela SysML e a geração dos artefatos necessários para a atividade, o diagrama e a tabela de Requisitos. As buscas pelas ferramentas foram realizadas na internet. 
Existem ferramentas comerciais disponíveis para geração de artefatos da SysML, como o Enterprise Architect, MagicDraw, Cameo Systems Modeler, UModel, Astah SysML e Rational Rhapsody Designer. Entre as principais foram encontradas duas ferramentas disponibilizadas gratuitamente, a Papyrus e a Modelio SysML Architect. A ferramenta Papyrus é uma ferramenta de código aberto utilizada para modelagem em projetos de software que consiste em um plugin para a plataforma de desenvolvimento Eclipse, e que fornece suporte para a SysML, inclusive na criação da tabela e diagrama de Requisitos da SysML [Papyrus 2018]. Desta forma, dentro das restrições de escolha, foi utilizada a ferramenta Papyrus para realização das atividades relacionadas no contexto do NTI. Outro ponto favorável para escolha da ferramenta Papyrus consiste na utilização da plataforma Eclipse para as atividades de codificação realizadas no NTI.

As atividades do subprocesso Analisar Requisitos estão descritas na Tabela 7 e a modelagem do subprocesso está representada na Figura 4. Na execução da atividade Resolver conflitos entre Requisitos, o Analista de Sistemas revisa os requisitos em busca de conflitos entre os mesmos, realizando os ajustes necessários por meio da coleta de informações específicas sobre o requisito, e em casos de requisitos com conflitos entre regras sugeridas por diferentes stakeholders é realizada uma reunião de conciliação, mediada pelo Analista de Sistemas, para definir um acordo. O conflito deve ser documentado em um documento tipo texto contendo os dados dos requisitos em conflito como ID e Nome, os stakeholders envolvidos e o resultado da negociação. Este artefato está descrito no processo como lista de conflitos. Caso não ocorram conflitos, é iniciada a atividade Priorizar Requisitos.

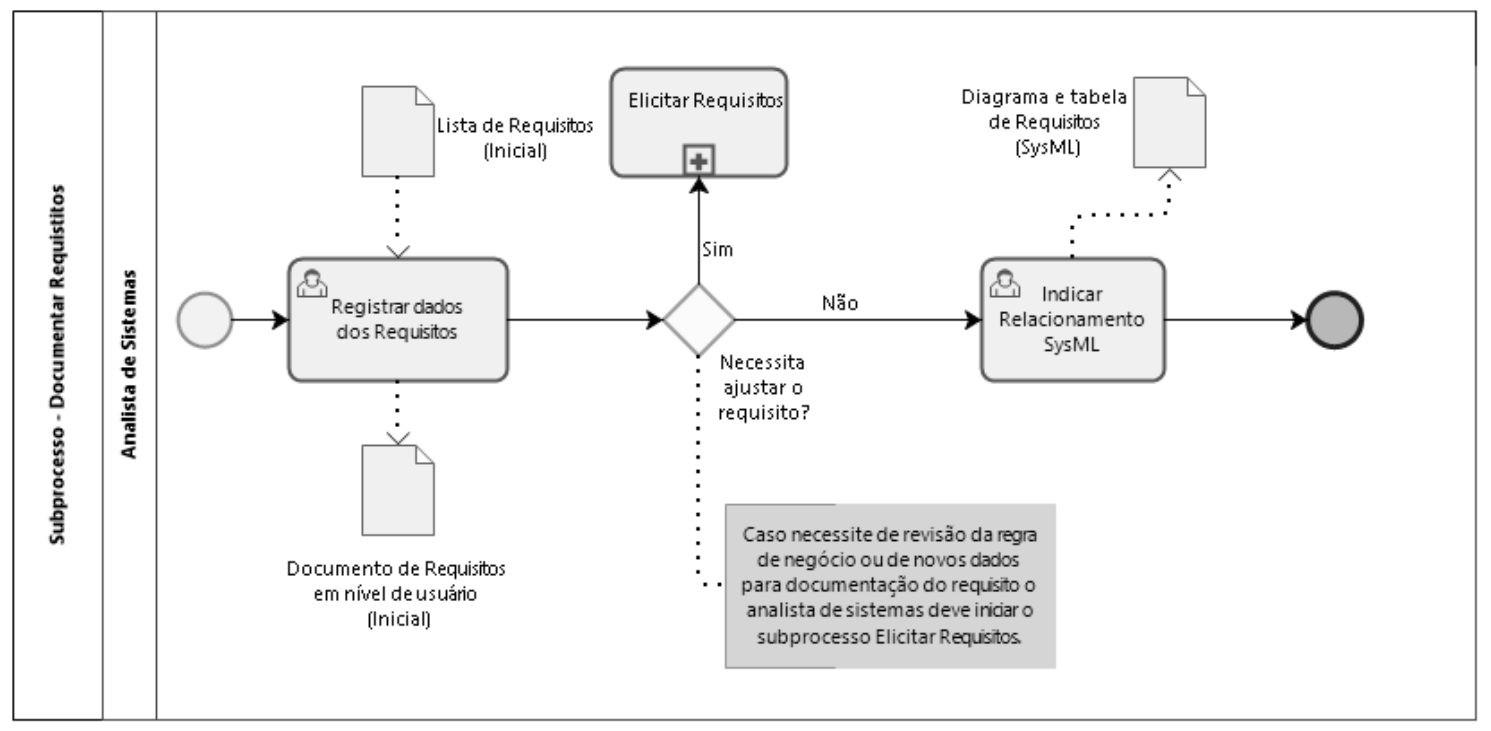

Figura 3. BPMN - Subprocesso Documentar Requisitos

Durante o primeiro ciclo de pesquisa-ação, os Analistas de Sistemas representantes da instituição sugeriram a inserção de um atributo para definir o grau de importância dos requisitos, tornando-se o atributo denominado "Prioridade" no template para documentação dos requisitos. Após uma análise baseada nos relatos encontrados 
na literatura para as características de cada técnica de priorização de requisitos encontrada, foi escolhida a técnica Atribuição Numérica para ser utilizada no processo, pela sua facilidade de utilização, pelo tempo baixo necessário para decisão do valor da prioridade e sua facilidade de priorização na manutenção e inserção de novos requisitos [Khan et al. 2015][Asghar et al. 2017]. Vale ressaltar que uma técnica mais detalhista pode ser utilizada em casos específicos, como também existe a possibilidade da utilização de duas ou mais técnicas em conjunto para obter um resultado mais exato na priorização.

Tabela 7. Atividades do Subprocesso Analisar Requisitos

\begin{tabular}{|l|l|}
\hline Nome da Atividade & \multicolumn{1}{c|}{ Detalhamento } \\
\hline \multirow{5}{*}{ Resolver conflitos entre Requisitos } & $\begin{array}{l}\text { Descrição: Analisar os Requisitos em busca de conflitos de regras } \\
\text { de negócio ou de definições técnicas. } \\
\text { Responsáveis: Analista de Sistemas } \\
\text { Participantes: Analista de Sistemas } \\
\text { Artefatos Gerados: Lista de Conflitos }\end{array}$ \\
\hline \multirow{2}{*}{ Priorizar Requisitos } & $\begin{array}{l}\text { Descrição: Priorização dos Requisitos indicando seu grau de } \\
\text { importância em Alto, Médio ou Baixo. } \\
\text { Responsáveis: Analista de Sistemas } \\
\text { Participantes: Cliente e Stakeholders } \\
\text { Artefatos Gerados:Documento de Requisitos em nível de usuário } \\
\text { (Requisitos priorizados) }\end{array}$ \\
\hline
\end{tabular}

O resultado da atividade Priorizar Requisitos consiste na geração do Documento de Requisitos em nível de usuário com a priorização de cada requisito realizada, sendo definido para cada requisito um grupo de prioridade como baixa, média e alta prioridade seguindo o proposto pela técnica atribuição numérica.

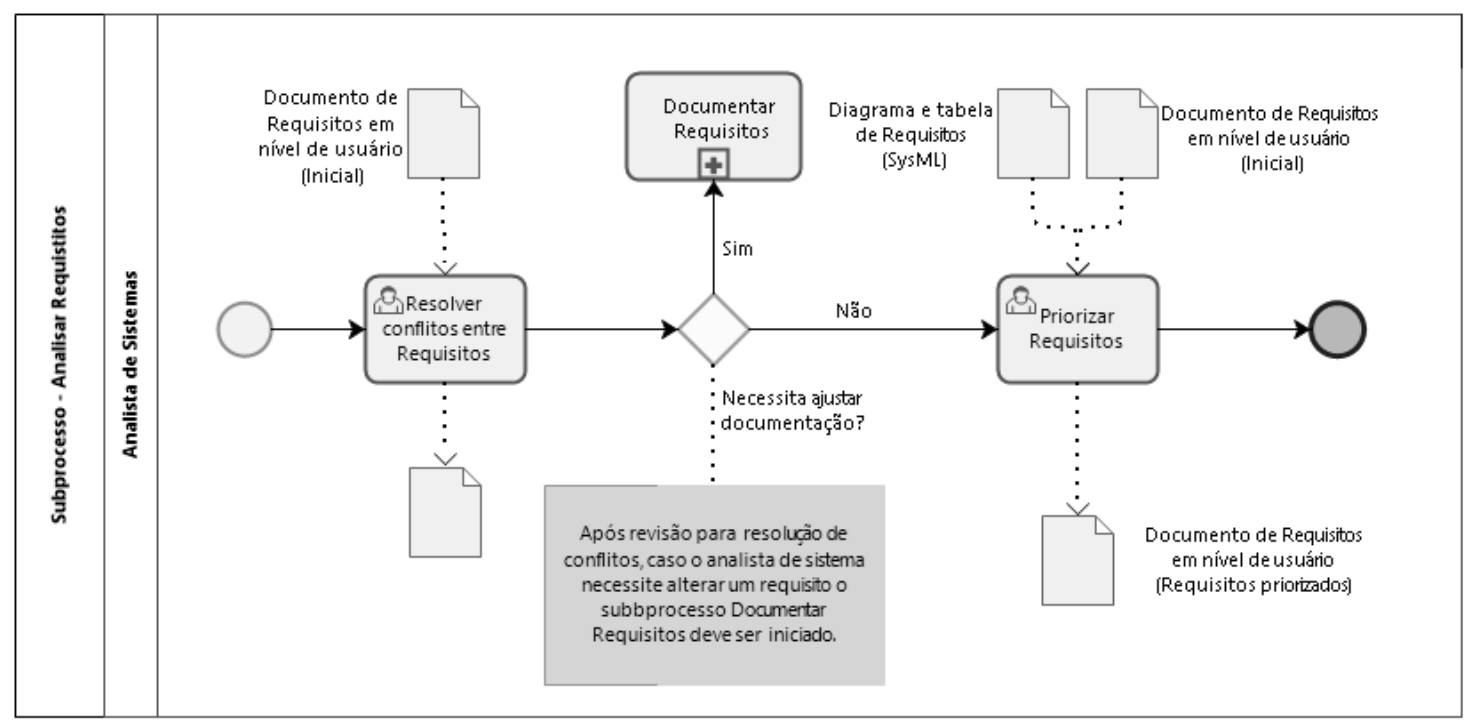

Figura 4. BPMN - Subprocesso Analisar Requisitos

A última etapa do processo consiste no subprocesso Validar Requisitos. Nesta etapa são realizadas inspeções para validar se os requisitos estão em conformidade com 
as características individuais e para um conjunto de requisitos proposto pela norma ISO/IEC/IEEE 29148:2011 utilizando a técnica de inspeção por meio de um checklist. A conclusão da atividade Validar Requisitos resulta na geração do Documento de Requisitos em nível de usuário final. A modelagem do subprocesso Validar Requisitos está representada na Figura 5.

Tabela 8. Atividades do Subprocesso Validar Requisitos

\begin{tabular}{|c|c|}
\hline Nome da Atividade & Detalhamento \\
\hline Executar Checklist de validação & $\begin{array}{l}\text { Descrição: Executar o checklist de validação do conjunto de } \\
\text { Requisitos em busca de inconformidades. } \\
\text { Responsáveis: Analista de Sistemas } \\
\text { Participantes: Analista de Sistemas } \\
\text { Artefatos Gerados: Documento de Requisitos em nível de usuário } \\
\text { (Final) }\end{array}$ \\
\hline Gerar Lista de Requisitos & $\begin{array}{l}\text { Descrição: Geração da Lista de Requisitos para ser usada em reunião } \\
\text { de aprovação com o Cliente. } \\
\text { Responsáveis: Analista de Sistemas } \\
\text { Participantes: Analista de Sistemas } \\
\text { Artefatos Gerados: Lista de Requisitos (Para aprovação) }\end{array}$ \\
\hline Aprovar Requisitos com o Cliente & $\begin{array}{l}\text { Descrição: Reunião entre Analista de Sistemas e Cliente para } \\
\text { aprovação dos requisitos do software. } \\
\text { Responsáveis: Analista de Sistemas } \\
\text { Participantes: Analista de Sistemas e Cliente } \\
\text { Artefatos Gerados: Lista de Requisitos (Aprovados) }\end{array}$ \\
\hline
\end{tabular}

A partir da Documentação de requisitos em nível de usuário final será gerada uma lista de requisitos com os dados necessários para aprovação com o Cliente, que analisará as especificações e em conjunto com os Analistas de Sistemas responsáveis pelo projeto aprovarão a documentação, esta atividade resulta num acordo entre as partes. $\mathrm{O}$ detalhamento dessas atividades está descrito na Tabela 8. Com o fim destas atividades é encerrado o subprocesso e consequentemente o processo principal.

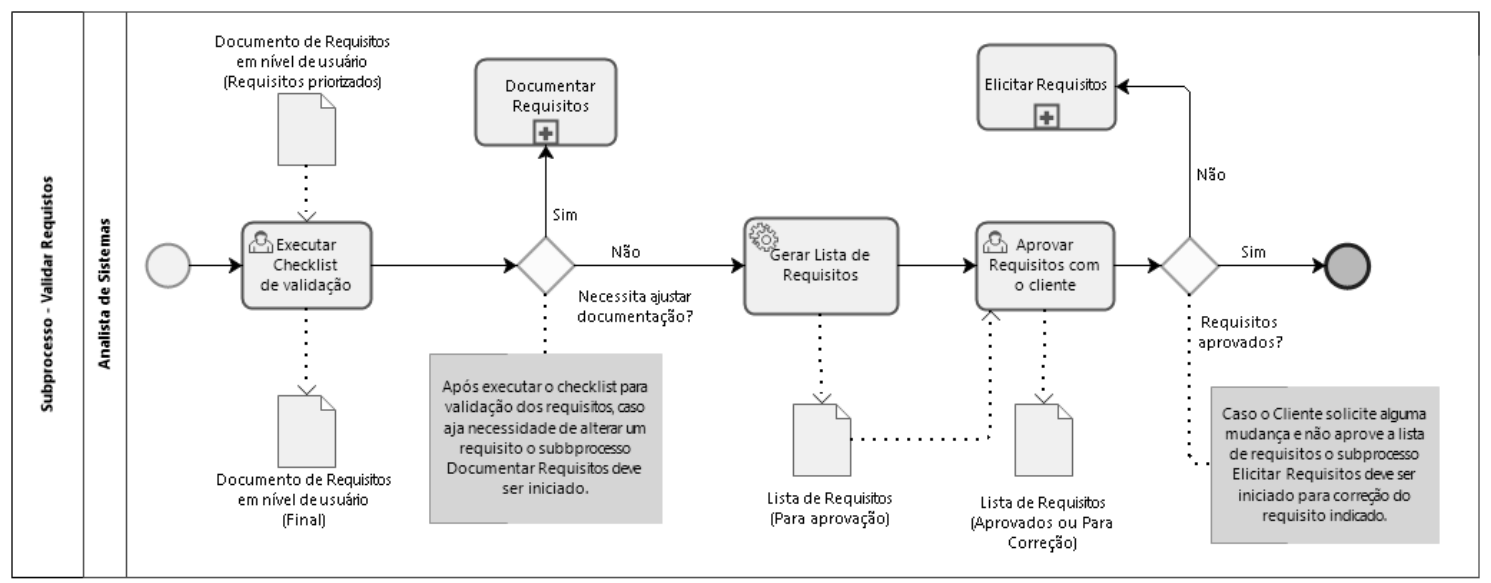

Figura 5. BPMN - Subprocesso Validar Requisitos

Os critérios de escolha das ferramentas utilizadas no processo estão direcionados ao contexto do NTI, ou seja, estas atividades podem ser realizadas com o auxílio de ou- 
tras técnicas e ferramentas que proporcionem os resultados esperados em cada atividade. As técnicas e ferramentas escolhidas são baseadas nas necessidades identificadas para o contexto em que foi aplicado este estudo de pesquisa-ação.

Os artefatos Documento de Requisitos em nível de usuário e Lista de Requisitos são utilizados como entrada em mais de uma atividade. Desta forma, estes artefatos são atualizados conforme a sua execução, resultando no mesmo artefato como saída, porém seus dados são modificados ou novos dados são inseridos de acordo com cada atividade.

\subsubsection{Análise Qualitativa das Atividades e Artefatos Propostos para o Processo}

Para obtenção do feedback dos participantes e seguindo o planejamento para o ciclo de pesquisa-ação, uma nova entrevista semi-estruturada foi realizada com os 12 participantes, caracterizados na Tabela 1. Nesta entrevista foram mantidos os mesmos moldes do primeiro ciclo, com 10 minutos de duração e com a coleta dos dados realizada pelo pesquisador entrevistador.

As perguntas desta entrevista possuem o intuito de coletar informações, referente as atividades a serem realizadas e os artefatos gerados, que ajudem em uma adequação do processo às necessidades e objetivos do NTI.

Durante a entrevista, foram realizadas as seguintes perguntas relacionadas às atividades:

1 Alguma atividade do processo proposto pode ser considerada desnecessária para execução do processo?

2 Alguma atividade deve ser adicionada ao processo?

3 É possível executar as atividades propostas no processo ou será necessário algum treinamento adicional?

Em relação aos artefatos, foram realizadas as seguintes perguntas:

4 Algum artefato gerado durante o processo pode ser considerado desnecessário?

5 Existe a necessidade de gerar algum artefato não descrito no processo?

Com relação à primeira e segunda perguntas, todos os participantes relatam em entrevista que as atividades propostas podem trazer melhor organização nos projetos de software quanto a definiçao dos requisitos e entendem que todas as atividades são necessárias e que nenhuma atividade adicional seja necessária. O participante P11 relatou uma insegurança quanto a sua contribuição na definição das atividades do processo devido o mesmo entender não possuir experiência suficiente para tal, contudo demonstrou-se comprometido com o estudo em andamento e que tem se esforçado para aprender mais sobre requisitos. Houve um questionamento de dois participantes (participantes P10 e P12) quanto a uma possível melhoria do processo após a execução e avaliação, uma vez que podem surgir novas atividades ou artefatos durante o uso do processo no NTI, em complemento questionaram se é possivel, caso necessário, modificar o processo depois de implantado. 
Em resposta à terceira pergunta, os participantes foram unânimes quanto a facilidade de entender as atividades por meio da sua descrição e modelagem do processo, destacando que podem ser realizadas seguindo as explicações oferecidas no workshop e no documento disponibilizado. Os participantes sugeriram que fosse realizado um treinamento do tipo simulação da execução do processo, para que seja alinhado e padronizado entre os participantes a sequência das atividades, um exemplo prático do uso da SysML e seus relacionamentos entre requisitos e também a criação dos artefatos nas ferramentas propostas. Os participantes P6 e P10 relataram a necessidade de um reforço por parte da coordenação do NTI quanto a necessidade dos Analistas de Sistemas seguirem todas as atividades propostas no processo. Essa situação se destaca devido o cenário atual no NTI não possuir um processo definido e relataram a preocupação quanto ao comprometimento de todos os envolvidos na execução das atividades. Esse relato foi repassado a coordenação do NTI que se prontificou em reforçar com os participantes sobre a importância da realização do trabalho.

Quanto à quarta e quinta perguntas, os participantes relataram, em sua totalidade, que os artefatos sugeridos podem atender as necessidades do NTI, não sendo necessário excluir ou inserir um novo artefato.

Encerradas as entrevistas de feedback, as atividades e artefatos propostos para o processo foram aprovados por todos os participantes, representantes do NTI e pesquisadores.

As respostas às entrevistas sugerem uma aceitação inicial dos participantes em relação às atividades e artefatos propostos, inclusive o template para documentação de requisitos. Os relatos também sugerem que a intervenção realizada por meio do primeiro e segundo ciclos promove uma reflexão entre os participantes representantes da instituição quanto a necessidade de realizar um processo sistemático nas atividades que envolvem a Engenharia de Requisitos. Essas atividades realizadas no primeiro e segundo ciclos também demonstram fragilidades quanto ao conhecimento teórico e prático por parte dos Analistas de Sistemas envolvidos.

\subsection{Terceiro Ciclo de Pesquisa-ação}

O terceiro ciclo de pesquisa-ação caracterizou-se pela execução e avaliação do processo proposto. Seguindo o mesmo planejamento do primeiro e do segundo ciclos de pesquisa-ação, um workshop foi realizado para revisar as atividades realizadas até o momento e alinhar os objetivos e atividades do terceiro ciclo entre pesquisadores e participantes. No terceiro ciclo os participantes realizaram as atividades conforme o processo apresentado no segundo ciclo para avaliação, envolvendo as ferramentas e geração dos artefatos propostos.

Mantendo a solicitação dos representantes da instituição, o workshop foi realizado em três reuniões realizadas no mês de julho de 2018. A primeira reunião teve a participação de cinco Analistas de Sistemas, a segunda teve a participação de quatro Analistas de Sistemas e a terceira de três Analistas de Sistemas. As reuniões do workshop seguiram o mesmo roteiro conforme descrito a seguir.

De início foram apresentados aos participantes os próximos passos na condução

iSys: Revista Brasileira de Sistemas de Informação (iSys: Brazilian Journal of Information Systems) 
do estudo, inclusive das atividades que seriam realizadas para execução e avaliação do processo. Também foi exposto aos participantes que o processo sugerido e aprovado por eles poderia em um momento futuro, após uma avaliação prática, sofrer alterações de melhoria. Tal esclarecimento foi motivado pelo questionamento realizado por parte dos participantes conforme descrito na Seção 4.3.3.

Em seguida, foi realizada uma revisão sobre o template criado e uma revisão do processo proposto mediante uma simulação das atividades do processo e dos artefatos gerados. Durante a simulação, de acordo com a atividade realizada, foi apresentada aos participantes a forma de acesso às ferramentas necessárias para execução das atividades. Esta etapa foi denominada de Preparação e foi detalhada na Seção 5.3.

Neste ciclo a reunião de feedback contemplou a avaliação por meio de respostas a um questionário e entrevista semi estruturada, realizada individualmente por cada participante seguindo os moldes dos ciclos anteriores. O planejamento, operação e os resultados da avaliação estão descritos de forma sistemática na Seção 5. Ficou definido entre pesquisadores e os participantes a data para conclusão das atividades do terceiro ciclo até o fim do mês de julho de 2018 .

\subsubsection{Avaliação da Execução do Processo Utilizando Etnografia}

Nesta Seção é apresentado um relato baseado em observação e no registro das tarefas realizadas pelos participantes durante a execução do processo e também foram apresentados os artefatos gerados em cada atividade.

Em relação ao ambiente de trabalho e ferramentas utilizadas, não houve relatos de problemas quanto ao acesso e utilização da ferramenta Redmine durante a execução do processo. A ferramenta Papyrus, utilizada na modelagem SysML, apresentou incompatibilidade com a versão Photon da IDE Eclipse, lançada em junho de 2018. Os participantes que já haviam atualizado a versão do Eclipse necessitaram realizar um downgrade para a versão Oxygen, compatível com a versão 1.4 do Papyrus SysML.

Em relação às atividades do subprocesso Elicitar Requisitos, não houve problemas relatados quanto a identificação dos stakeholders e preenchimento da lista de stakeholders. Uma vez que os requisitos já haviam sido identificados anteriormente, os Analistas de Sistemas revisaram os requisitos e coletaram os dados necessários para preenchimento do template sem relatos de dificuldades.

Em relação às atividades do subprocesso Documentar Requisitos, os Analistas de Sistemas realizaram o registro dos dados dos requisitos na ferramenta Redmine. Neste momento, para todos os projetos e participantes envolvidos houve dúvida em relação aos tipos de relacionamentos entre requisitos de acordo com a SysML. Para sanar as dúvidas houve intervenção de um pesquisador, porém os exemplos utilizados na explicação não abordaram o contexto dos projetos em execução. As dúvidas sobre a SysML foram sanadas e as atividades do processo seguiram seu fluxo. A modelagem do Diagrama de Requisitos na ferramenta Papyrus ocorreu sem relatos de dificuldade. A Figura 6 apresenta um exemplo de Diagrama de Requisitos modelado durante o processo. 


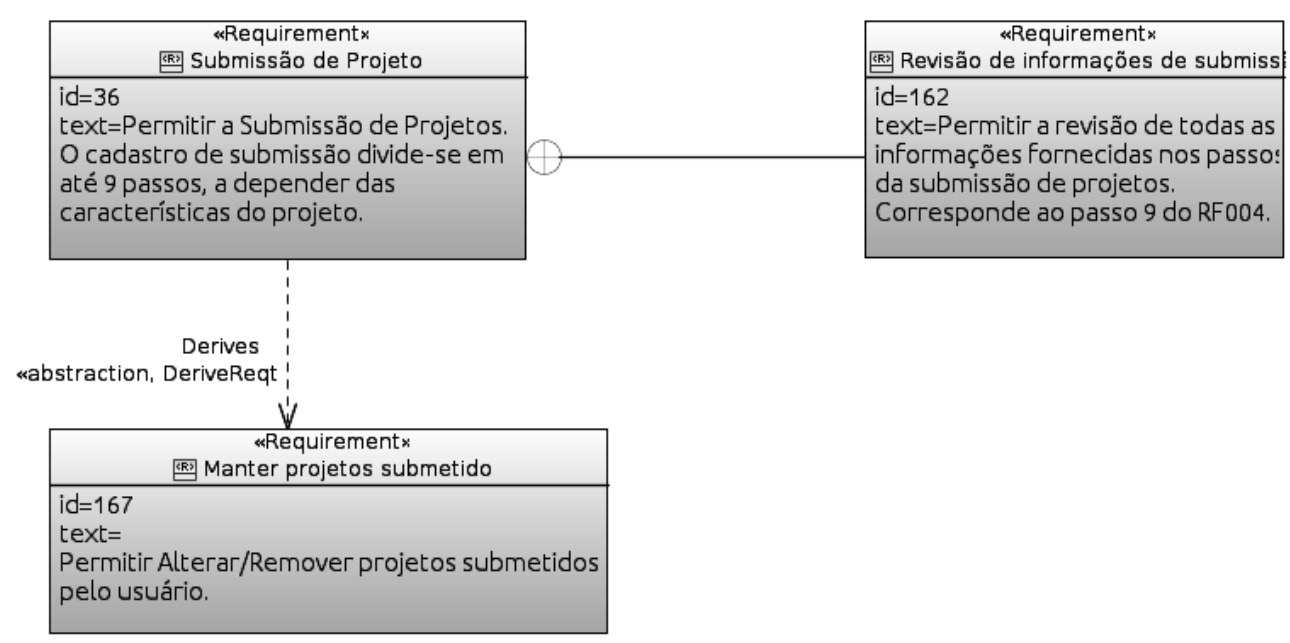

Figura 6. Exemplo: Diagrama de Requisitos da SysML (Papyrus)

Em relação às atividades do subprocesso Analisar Requisitos, a atividade Resolver conflitos entre requisitos foi realizada sem problemas relatados. A atividade Priorizar requisitos transcorreu sem relatos de problema. Em relação às atividades do subprocesso Validar Requisitos, durante execução do checklist de validação houve necessidade de intervenção do pesquisador para sanar dúvidas em relação a perguntas do checklist. Um ponto identificado pelo pesquisador observador foi a dificuldade por parte dos participantes quanto aos conceitos das características de qualidade utilizadas na validação. Em seguida, foram gerados os artefatos Lista de Requisitos e Documento de Requisitos por meio da ferramenta Redmine.

Por fim, a atividade Aprovar Requisitos foi realizada por meio da apresentação dos artefatos gerados e aprovação da Lista e do Documento de Requisitos e o processo foi encerrado. Todos os artefatos gerados foram coletados por um pesquisador após encerramento das atividades do processo. Exemplos desses artefatos são apresentados no Apêndice A deste artigo.

A intervenção foi encerrada após a execução do processo, preenchimento do questionário de avaliação e realização da entrevista final. A pesquisa-ação foi concluída com a execução dos três ciclos planejados inicialmente.

\section{Avaliação do Processo}

\subsection{Definição do Método de Avaliação}

Para a avaliação do processo foram seguidas as etapas propostas por Wohlin et al. [Wohlin et al. 2012] para condução de um experimento in vivo, a fim de minimizar possíveis ameaças ao resultado. As seguintes fases foram analisadas durante o processo de avaliação: fase de planejamento, operação e de interpretação dos resultados. A avaliação foi executada durante a realização do terceiro ciclo de pesquisa-ação. 


\subsubsection{Objetivo da Avaliação}

O objetivo da avaliação é analisar o processo para elicitar e documentar requisitos de software em nível de usuário, com a finalidade de avaliar seus resultados, com respeito à eficácia do processo, do ponto de vista dos Analistas de Sistemas participantes da pesquisa-ação, no contexto da instituição participante. Este objetivo é formalizado usando parte do modelo GQM proposto por Basili e Weiss [Basili and Weiss 1984].

\subsubsection{Questões e Métricas}

A partir do objetivo, as seguintes questões e métricas relacionadas foram definidas, conforme apresentado na Tabela 9.

Tabela 9. Questões e Métricas

\begin{tabular}{|l|l|}
\hline Questões & Métricas \\
\hline $\begin{array}{l}\text { Q1 - Houve melhora no resultado das atividades } \\
\text { realizadas, de acordo os dados coletados a partir } \\
\text { dos artefatos gerados anteriormente em relação aos } \\
\text { dados dos artefatos produzidos com a execução do } \\
\text { processo? }\end{array}$ & $\begin{array}{l}\text { M1 - quant. de stakeholders identificados; } \\
\text { M3 - quant. de requisitos identificados; } \\
\text { M4 - quant. de requisitos com relacionamentos } \\
\text { com um ou mais requisitos identificados. }\end{array}$ \\
\hline $\begin{array}{l}\text { Q2 - O processo proposto alcançou os resultados } \\
\text { esperados pelos Analistas de Sistemas participantes } \\
\text { da pesquisa-ação? }\end{array}$ & $\begin{array}{l}\text { Avaliação por meio de questionário aplicado aos } \\
\text { participantes. }\end{array}$ \\
\hline $\begin{array}{l}\text { Q3 - O resultado geral do processo é satisfatório do } \\
\text { ponto de vista dos Analistas de Sistemas } \\
\text { participantes? }\end{array}$ & $\begin{array}{l}\text { Avaliação subjetiva dos Analistas de Sistemas } \\
\text { realizada por meio de entrevista. }\end{array}$ \\
\hline
\end{tabular}

A avaliação foi realizada por meio da coleta de dados do processo e da aplicação de questionário e entrevista semi estruturadas. Uma escala Likert de 5 pontos foi proposta para medir as respostas do questionário, fornecendo um conjunto de respostas a cada afirmação. A escala variou de (1) discordo totalmente, (2) discordo, (3) neutro, (4) concordo a (5) concordo fortemente.

A partir da questão Q2, de acordo com a Tabela 9, foram definidas nove sentenças para o questionário, e a partir da questão Q3 foram definidas as cinco perguntas utilizadas na entrevista. As sentenças e perguntas são apresentadas na análise dos resultados apresentados na Seção 5.4 .

\subsection{Planejamento}

A avaliação foi realizada por meio da execução do processo proposto aplicado a cinco projetos de software em desenvolvimento com a participação dos Analistas de Sistemas envolvidos neste estudo de pesquisa-ação. As atividades foram realizadas nas dependências do NTI.

Os projetos utilizados na avaliação já possuíam no momento em que iniciou-se este estudo um conjunto de requisitos elicitados e os stakeholders de cada projeto. Sendo assim, a etapa de Elicitação de Requisitos que consiste nas atividades de Identificar os 
stakeholders do projeto e Identificação dos requisitos já haviam sido realizadas. Contudo, as atividades foram refeitas pelos participantes.

A Tabela 10 apresenta a caracterização dos projetos utilizados para avaliação, incluindo os Analistas de Sistemas envolvidos por meio de sua identificação no estudo de acordo com a Tabela 1 .

Tabela 10. Projetos usados na avaliação

\begin{tabular}{|l|l|l|l|}
\hline ID & Projeto & Descrição & Participantes \\
\hline A & Boletim de serviços & $\begin{array}{l}\text { O módulo Boletim de Serviço tem o objetivo de } \\
\text { tornar público os atos administrativos e normativos } \\
\text { postos em prática no âmbito da Instituição. O } \\
\text { módulo permite à instituição publicar os boletins de } \\
\text { serviços, autorizar a adição e adicionar } \\
\text { informativos aos boletins, além do cadastro, } \\
\text { remoção e consultas de boletins e informativos. }\end{array}$ & P3, P6; \\
\hline B & Jubilamento & $\begin{array}{l}\text { O módulo permite a identificação, notificação e } \\
\text { jubilamento de alunos de graduação da instituição. } \\
\text { O jubilamento é o processo em que a universidade } \\
\text { desliga alunos que extrapolaram o prazo máximo } \\
\text { de conclusão do curso. }\end{array}$ & P12; \\
\hline C & Lato Sensu & $\begin{array}{l}\text { O módulo Lato Sensu possibilita controlar e } \\
\text { gerenciar os cursos Lato existentes na Instituição. }\end{array}$ & P2, P7, P11; \\
\hline D & Restaurante universitário & $\begin{array}{l}\text { O módulo permite gerenciar os restaurantes } \\
\text { universitários da instituição permitindo aos } \\
\text { usuários do restaurante adquirirem créditos para } \\
\text { refeições e o acompanhamento diário da utilização } \\
\text { desses créditos, e os gestores controlam operações } \\
\text { administrativas relacionadas aos restaurantes } \\
\text { distribuídos entre os campi da instituição. }\end{array}$ & $\mathrm{P} 1, \mathrm{P} 8 ;$ \\
\hline E & Projetos e Convênios & $\begin{array}{l}\text { O módulo de Projetos e Convênios é responsável } \\
\text { pela gerência financeira dos projetos da instituição, } \\
\text { bem como o controle de convênios com terceiros. }\end{array}$ & P4, P5, P9, P10. \\
\hline
\end{tabular}

As variáveis independentes deste estudo são os Analistas de Sistemas selecionados para participarem da pesquisa-ação e as técnicas e métodos utilizados pelo NTI em seus processos de desenvolvimento de software.

As variáveis dependentes deste estudo são o número de stakeholders identificados, o número de requisitos gerados, número de conflitos identificados e o número de requisitos com algum tipo de relacionamento com outro requisito. Esses dados foram obtidos a partir da execução do processo. Somente foram confrontadas com dados anteriores as variáveis número de stakeholders identificados e número de requisitos gerados, as demais variáveis não foram confrontadas por não terem sido computadas anteriormente nas atividades realizadas pelos Analistas de Sistemas do NTI. Também são variáveis dependentes as respostas dos Analistas de Sistemas ao questionário aplicado e respostas às entrevistas realizadas no final desta avaliação.

A seleção dos participantes desta avaliação ocorreu por conveniência do NTI. A caracterização dos participantes está descrita na Seção 4.1 deste estudo.

O processo de instrumentação foi realizado inicialmente com a configuração do 
ambiente para o experimento e planejamento de coleta dos dados. $\mathrm{O}$ ambiente utilizado foi o mesmo utilizado no dia a dia de trabalho dos participantes, ou seja, cada participante realizou as atividades em sua estação de trabalho real.

$\mathrm{O}$ acesso à ferramenta Redmine ocorreu por meio de acesso via intranet, com acesso restrito somente aos participantes deste estudo por meio de usuário e senha específicos para cada participante.

A instalação da ferramenta Papyrus foi realizada em cada estação de trabalho por meio do ambiente de desenvolvimento Eclipse (versão Oxygen), de domínio dos participantes. A ferramenta está disponível para instalação automática via interface do próprio Eclipse. A versão utilizada foi a Papyrus SysML 1.4.

Cada participante teve cinco dias para execução do processo, contados após realização do workshop. Por fim, após execução das atividades do processo e geração dos artefatos, cada Analista respondeu ao questionário de pesquisa individualmente na presenca de um pesquisador.

\subsection{Operação}

\subsubsection{Preparação}

A preparação da avaliação foi realizada por meio do workshop realizado no terceiro ciclo de pesquisa-ação e foram apresentadas aos participantes as etapas de preparação para execução do processo.

A seguir, são enumeradas as etapas de preparação para a execução do processo.

1 Demonstração da execução das atividades do processo proposto: foi realizada revisão e simulação das atividades propostas no processo. Esta etapa durou cerca de 90 minutos e foi realizada por um pesquisador, incluindo o tempo gasto nas etapas 2 e 3 subsequentes.

2 Treinamento da ferramenta Redmine: pela facilidade de uso, foi realizado um treinamento de 30 minutos com os Analistas de Sistemas, ministrado por um pesquisador, a fim de que os participantes pudessem se familiarizar com a documentação dos requisitos na ferramenta e com a geração dos artefatos do processo.

3 Treinamento da ferramenta Papyrus: pela facilidade de uso, foi realizado um treinamento de 30 minutos com os Analistas de Sistemas, ministrado por um pesquisador, a fim de que os participantes pudessem se familiarizar com a ferramenta de geração dos artefatos da SysML.

Em relação ao ambiente, todos os computadores foram preparados para que os participantes estivessem sob as mesmas condições de trabalho. Foi apresentado, a cada Analista de Sistemas, um documento contendo uma descrição detalhada do processo e das atividades que seriam realizadas por eles em caso de eventuais dúvidas.

\subsubsection{Execução}

$\mathrm{Na}$ etapa de execução tudo que foi planejado nas etapas anteriores foi concretizado. Nesta etapa aconteceu a efetiva execução das atividades realizadas no processo, 
incluindo a geração dos artefatos.

\subsubsection{Coleta dos Dados}

A coleta dos dados foi realizada por meio do preenchimento do questionário e entrevista, ambos aplicados na presença do pesquisador. Os participantes responderam a um questionário composto de 9 sentenças em que expressaram suas opiniões categorizadas de acordo com cada afirmação. A entrevista contêm 5 perguntas e durou cerca de 10 minutos, os dados das respostas foram coletados pelo pesquisador entrevistador. Também foi realizada a coleta de dados nos artefatos produzidos antes da realização deste estudo, referente ao número de stakeholders identificados anteriormente e o número de requisitos elicitados, e também foram coletados os dados dos artefatos produzidos durante a execução do processo.

\subsubsection{Validação dos Dados}

A aplicação do questionário foi realizada de forma individual e presencial. Diante deste contexto, foi realizada uma análise das respostas individuais para garantir que todas haviam sido preenchidas corretamente. Após encerramento das atividades foi realizada uma análise qualitativa das respostas. Os dados coletados foram submetidos a uma análise estatística descritiva.

\subsection{Interpretação dos Resultados}

\subsubsection{Análise Quantitativa}

Este estudo utilizou métodos quantitativos para analisar os dados coletados durante a execução do processo e para analisar as respostas ao questionário aplicado aos participantes. Esses dados coletados e os dados do questionário são classificados como variáveis dependentes neste estudo. Não foi avaliado se os resultados alcançados pelos diferentes participantes em um mesmo projeto coincidiram. Os dados coletados nos artefatos possibilitaram analisar os resultados obtidos com a execução do processo, fornecendo informações para responder a questão Q1 da Tabela 9.

Tabela 11. Quant. de Stakeholders

\begin{tabular}{|c|c|c|}
\hline Projeto & Antes & Depois \\
\hline A & 01 & 06 \\
\hline B & 01 & 05 \\
\hline C & 01 & 04 \\
\hline D & 02 & 11 \\
\hline E & 01 & 04 \\
\hline
\end{tabular}

Tabela 12. Quant. de Requisitos

\begin{tabular}{|c|c|c|}
\hline Projeto & Antes & Depois \\
\hline A & 66 & 62 \\
\hline B & 26 & 26 \\
\hline C & 42 & 42 \\
\hline D & 23 & 38 \\
\hline E & 115 & 115 \\
\hline
\end{tabular}

Em análise aos dados apresentados na Tabela 11, após a execução do processo houve um aumento no número de stakeholders identificados para todos os projetos analisados. Analisando os dados da lista de stakeholders obtida durante a execução do processo, podemos sugerir que documentar os vários tipos de stakeholders, como usuários 
responsáveis pela regra de negócio e pela aceitação do sistema, e não apenas o usuário demandante do projeto provocou tal incremento.

Os resultados apresentados na Tabela 12 indicam uma alteração na quantidade de requisitos identificados nos projetos A e D após utilização do processo. Os demais projetos mantiveram a mesma quantidade de requisitos identificados anteriormente. Os novos stakeholders identificados não foram consultados sobre os requisitos do sistema devido a fase de elicitação do projeto já ter sido concluída no momento da avaliação. Sendo assim, existe a possibilidade de que outros requisitos não tenham sido identificados, o que poderia aumentar a quantidade de requisitos identificados de cada projeto.

Tabela 13. Quant. de conflitos entre requisitos identificados

\begin{tabular}{|c|c|}
\hline Projetos & Conflitos entre requisitos \\
\hline A & 04 \\
\hline B & 03 \\
\hline C & 01 \\
\hline D & - \\
\hline E & 04 \\
\hline
\end{tabular}

No projeto A houve uma redução da quantidade de requisitos motivada pela resolução de conflitos identificados conforme apresentado na Tabela 13. Os conflitos identificados tiveram como resolução o cancelamento de quatro requisitos, o que provocou a diminuição da quantidade de requisitos. O projeto $\mathrm{D}$ apresentou um aumento do número de requisitos provocado pela identificação de requisitos documentados com mais de uma regra de negócio ou restrição para o sistema, contrariando a característica de singularidade proposta para documentação de um requisito. Os Analistas de Sistemas envolvidos no projeto $\mathrm{D}$ decidiram por revisar os requisitos e separar cada requisito de forma a contemplar apenas um requisito por registro. Este efeito provocou a decisão dos Analistas de Sistemas do projeto D em não realizarem a documentação dos conflitos, entendendo que os conflitos entre requisitos foram solucionados nesta ação de documentar apenas um requisito por registro. Por este motivo não há registro do número de conflitos identificados para o projeto $\mathrm{D}$, conforme apresentado na Tabela 13.

Os número de conflitos entre requisitos identificados para os demais projetos são apresentados também na Tabela 13. Para os projetos B, C e E os conflitos foram solucionados mediante alteração da regra de negócio descrita nos requisitos conflitantes.

Tabela 14. Quant. de requisitos com relacionamentos identificados

\begin{tabular}{|c|c|c|}
\hline Projetos & Total de requisitos & $\mathrm{N}^{\mathrm{o}}$ de relacionamentos \\
\hline A & 62 & 50 \\
\hline B & 26 & 20 \\
\hline C & 42 & 11 \\
\hline D & 38 & 21 \\
\hline E & 115 & 69 \\
\hline
\end{tabular}

A Tabela 14 apresenta a quantidade de requisitos com relacionamentos com um ou mais requisitos identificados. O resultado obtido sugere que o número de requisitos 
com relacionamentos do projeto $\mathrm{A}$ e $\mathrm{B}$ equivale a $81 \%$ do total de requisitos, para o projeto $\mathrm{C}$ equivale a $27 \%$, para o projeto $\mathrm{D}$ equivale a $56 \%$ e para o projeto $\mathrm{E}$ equivale a $69 \%$ do total de requisitos. Esses números percentuais representam a cobertura da rastreabilidade entre os requisitos identificadas por meio da SysML. Esses dados sugerem que a utilização da SysML permitiu identificar e documentar a rastreabilidade entre os requisitos dos projetos.

Tabela 15. Respostas ao Questionário

\begin{tabular}{|l|c|c|c|c|c|c|}
\hline Sentenças de 1 a 9 & $\mathbf{1}$ & $\mathbf{2}$ & $\mathbf{3}$ & $\mathbf{4}$ & $\mathbf{5}$ & $\mathbf{p o s}$ \\
\hline $\begin{array}{l}\text { 1 - O template utilizado para documentação fornece as informações ne- } \\
\text { cessárias para a definição de um requisito de software no contexto desta }\end{array}$ & 0 & 0 & 0 & 7 & 5 & 12 \\
Instituição. & & & & & \\
\hline $\begin{array}{l}2-\text { O Diagrama de Requisitos da SysML permite complementar a } \\
\text { documentação dos requisitos. }\end{array}$ & 0 & 0 & 1 & 6 & 5 & 11 \\
\hline $\begin{array}{l}\text { 3- O Diagrama de Requisitos da SysML permite melhor visualização dos } \\
\text { requisitos, incluindo seus relacionamentos. }\end{array}$ & 0 & 0 & 0 & 6 & 6 & 12 \\
\hline $\begin{array}{l}\text { 4 - A Tabela de Requisitos da SysML permite melhor organização dos } \\
\text { requisitos, incluindo seus relacionamentos. }\end{array}$ & 0 & 1 & 0 & 6 & 5 & 11 \\
\hline $\begin{array}{l}\text { 5- A Tabela de Requisitos da SysML permite melhor visualização de um } \\
\text { conjunto de requisitos. }\end{array}$ & 0 & 0 & 1 & 6 & 5 & 11 \\
\hline $\begin{array}{l}\text { 6- O processo para elicitação e documentação de requisitos em nível de } \\
\text { usuário atende as necessidades da instituição em relação aos artefatos ge- } \\
\text { rados. }\end{array}$ & 0 & 0 & 1 & 10 & 1 & 11 \\
\hline $\begin{array}{l}\text { 7 - É fácil para mim executar as atividades do processo e chegar ao resul- } \\
\text { tado esperado. }\end{array}$ & 0 & 1 & 0 & 9 & 2 & 11 \\
\hline $\begin{array}{l}\text { 8 - Os artefatos gerados no processo são suficientes para documentação } \\
\text { dos requisitos em nível de usuário de acordo com as necessidades da } \\
\text { Instituição. }\end{array}$ & 0 & 2 & 2 & 4 & 4 & 8 \\
\hline $\begin{array}{l}\text { 9 - As ferramentas utilizadas permitem o desenvolvimento das atividades } \\
\text { relacionadas ao processo proposto. }\end{array}$ & 0 & 0 & 0 & 6 & 6 & 12 \\
\hline
\end{tabular}

Em resposta à Questão Q1 da Tabela 9, a análise dos dados coletados sugere que o processo proporcionou melhora na quantidade de stakeholders identificados. Outro ponto relevante foram os ajustes realizados na quantidade de requisitos identificados em parte dos projetos, provocado pela resolução dos conflitos identificados e pela necessidade de atender as características de qualidade sugeridas no processo para a documentação dos requisitos. Esses requisitos não identificados anteriormente poderiam ocasionar mudanças com impactos negativos no desenvolvimento do projeto, isto foi considerado uma melhoria. Dentre os resultados coletados nesta etapa, a identificação da rastreabilidade entre os requisitos se destaca pela quantidade de requisitos com relacionamentos em relação ao total de requisitos identificados, o que sugere que o processo pode melhorar a análise de impacto em futuras alterações de requisitos ou na inserção de novos requisitos para os projetos. Diante da análise realizada, acerca dos dados coletados com a execução do processo, pode-se inferir que houve melhora no resultado das atividades realizadas.

Para responder à questão Q2 da Tabela 9 foram analisadas as respostas ao questionário conforme apresentado na Tabela 15. Para respostas positivas (pos) foram considerados as indicações de "concordo" e "concordo fortemente" (valores 4 ou 5), e para respostas negativas foram considerados "discordo totalmente" e "discordo" (valores 1 ou 
2).

Em análise aos dados apresentados na Tabela 15, verifica-se que os participantes da pesquisa mostraram alta concordância em relação às sentenças 1,3 e 9 . As sentenças de número 2, 5 e 6, apresentam alta aceitação por parte dos participantes, com apenas um registro de valor "neutro" aplicado para cada sentença.

A sentença de número 4 também apresentou um alto número de respostas positivas, tendo apresentado apenas uma rejeição. O Analista de Sistemas P10 indicou a rejeição sob o motivo de acreditar que será difícil manter a organização da Tabela de Requisitos da SysML quando existir relacionamentos entre uma grande quantidade de requisitos.

A sentença de número 7 apresentou alta concordância da maioria dos participantes. Contudo, o Analista de Sistemas P5 indicou uma rejeição sob o motivo de alegar dificuldade para executar a atividade Indicar relacionamento SysML no subprocesso Documentar Requisitos. Segundo o mesmo, ele teve dificuldade em identificar o tipo de relacionamento. O Analista de Sistemas P5 conclui indicando que não sentiu dificuldade durante execução das outras atividades do processo.

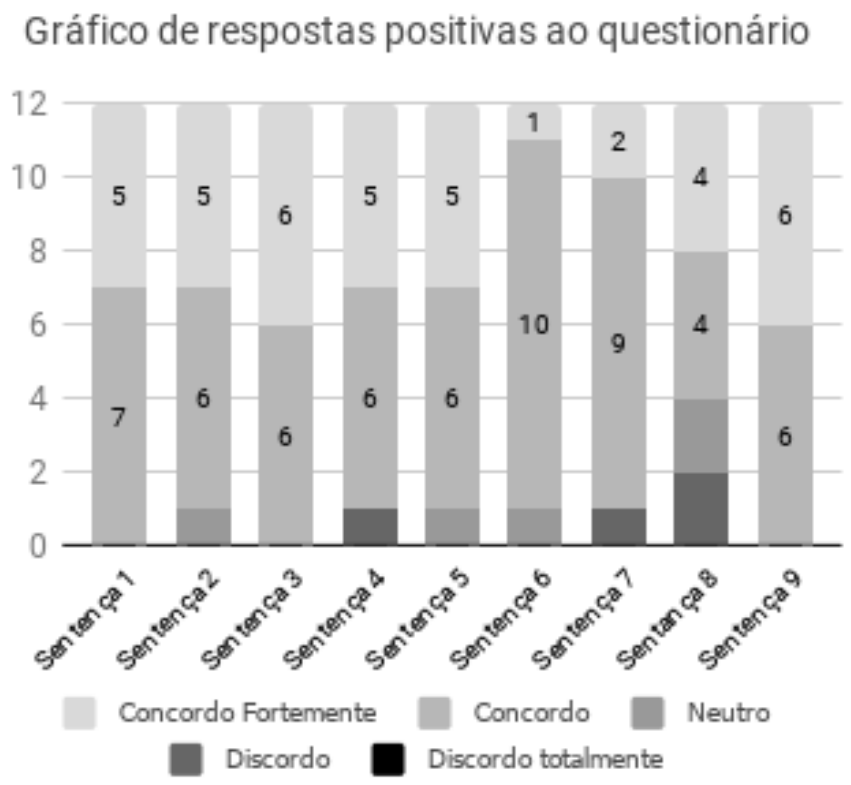

Figura 7. Gráfico: Respostas positivas ao questionário

Para a sentença de número 8 a maioria dos participantes indicou valores positivos. Todavia, houve entre as respostas indicações de dois valores "neutro" e duas indicações de valor "discordo". Os Analistas de Sistemas P10 e P12 indicaram rejeição sob a mesma justificativa. Os Analistas de Sistemas P10 e P12 acreditam que associando à documentação de requisitos em nível de usuário alguns artefatos como diagramas de processos de negócio, protótipos de interface e requisitos em nível de sistema, terão uma 
documentação mais completa. Contudo, durante as entrevistas relacionadas aos artefatos necessários para utilização na documentação de requisitos para a instituição, realizada no segundo ciclo de pesquisa-ação, tais artefatos não foram mencionados.

A partir dos dados apresentados na Figura 7, conclui-se que 91,7 \% dos Analistas de Sistemas têm opinião positiva (4 ou superior) para a maioria do questionário. Nenhuma sentença apresentou o valor "discordo totalmente" como resposta. Desta forma, em resposta a questão Q2 da Tabela 9, os resultados obtidos sugerem que o processo alcançou os resultados esperados pelos Analistas de Sistemas participantes deste estudo.

\subsubsection{Análise Qualitativa}

Esta análise refere-se à questão Q3 de acordo com a Tabela 9. Para responder esta questão de ordem qualitativa foram analisadas as respostas à entrevista, classificadas como variáveis dependentes neste estudo.

As questões da entrevista, suas respostas individuais e a análise realizada estão descritas a seguir:

- Pergunta 1 - De que forma o processo proposto pode melhorar a comunição entre os envolvidos no projeto em relação aos requisitos?

Em resposta à primeira pergunta, 100\% dos Analistas de Sistemas indicam que o processo trouxe melhorias na comunicação entre os envolvidos do projeto. A maioria dos entrevistados atribui melhora na comunicação devido o processo promover uma documentação detalhada dos requisitos que resulta numa visão mais completa do software a ser desenvolvido. Os Analistas de Sistemas P3 e P6 relatam que a lista de Stakeholders ajuda nessa comunicação sob o argumento de que a existência de um documento com os dados dos stakeholders facilita a localização e comunicação com os envolvidos. Entre as respostas que se destacam pode-se citar o relato do Analista de Sistemas P5 que possui mais de dez anos de experiência na instituição: "o processo nos solicita a identificar e plotar os relacionamentos, o que nos leva a entender melhor não somente os requisitos em si, mas os requisitos como um conjunto. Isso permite nivelar o entendimento acerca dos requisitos entre a equipe de desenvolvimento e os stakeholders, melhorando a comunicação".

- Pergunta 2 - Seguindo as atividades propostas no processo é possível definir a documentação de requisitos em nível de usuário de um novo projeto de software? Justifique sua resposta.

Em resposta à segunda pergunta, 100\% dos entrevistados afirmam que sim, é possível definir a documentação de requisitos em nível de usuário de um novo software seguindo o processo proposto. Entre as respostas, o Analista de Sistemas P1 destaca que é possível definir o escopo de um novo projeto a partir das informações obtidas na documentação. Os Analistas de Sistemas P3, P4 e P11 destacam que a documentação gerada proporciona transparência e possibilita aos envolvidos visualizarem e analisarem os requisitos elicitados, e que isso facilita a validação e permite definir de forma clara o que os stakeholders realmente necessitam. O Analista de Sistemas P10 relata que é possível definir a documentação 
desde que os envolvidos no processo de elicitação de requisitos comprometam-se a seguir o modelo proposto. Os Analistas de Sistemas P9 e P12 destacam a rastreabilidade entre requisitos obtida a partir da documentação gerada. Os demais participantes justificam sua aceitação indicando que por meio do processo podem criar a documentação necessária devido o processo possuir uma documentação e atividades bem definidas. Também indicam como justificativas a identificação dos stakeholders corretos para elicitação e validação dos requisitos, redução de falhas na documentação motivadas pela atividade de validação, e envolvimento dos stakeholders na priorização e validação dos requisitos.

\section{- Pergunta 3 - Quais melhorias o processo proposto pode trazer para realização} das suas atividades na instituição?

Em resposta à terceira pergunta, os Analistas de Sistemas envolvidos na avaliação mostraram diferentes perspectivas em relação as melhorias que o processo pode trazer para execução de suas atividades relacionadas à definição dos requisitos. Os Analistas citam comumente as melhorias voltadas para melhor organização e padronização das atividades e resultados. Outro ponto comum entre as respostas é a documentação dos relacionamentos entre os requisitos o que segundo a maioria dos Analistas melhora a rastreabilidade. Quanto às melhorias na rastreabilidade destacam-se as seguintes respostas: "fica mais claro quais requisitos vão ser impactados"; "maior segurança de ter relacionado corretamente os requisitos em questão"; "pode melhorar o levantamento de requisitos e principalmente seus relacionamentos"; "possibilita uma visão macro dos requisitos, este aspecto é de grande utilidade pois ajuda a entender o impacto do requisito no sistema"; "melhor visualização das relações entre requisitos". Entre as diferentes melhorias indicadas destacam-se a geração de artefatos por meio da ferramenta utilizada, maior segurança quanto a definição dos requisitos para o Analista de Sistemas e para o gestor, e uma melhor identificação dos stakeholders.

- Pergunta 4 - Você se sente preparado para trabalhar com o processo para elicitação e documentação de requisitos em nível de usuário? Justifique sua resposta.

Com relação à quarta pergunta, a maioria dos Analistas de Sistemas acreditam que sim, estão preparados para executar as atividades propostas no processo. Apenas o Analista de Sistemas P5 diverge dos demais respondendo que não se sente preparado por entender que teve muita dificuldade em indicar os relacionamentos entre requisitos conforme a SysML. Este é um relato semelhante ao apresentado em sua resposta ao questionário, discutido na Seção 5.4.1. Os Analistas de Sistemas P4, P6, P8, P9 e P11 descrevem que se sentem preparados uma vez que o processo possui atividades bem definidas e de fácil entendimento e execução. Os Analistas de Sistemas P1, P2, P10 e P12 consideram-se preparados sob a justificativa de possuírem conhecimento teórico e prático suficiente para realização das atividades.

- Pergunta 5 - Você gostaria de usar o processo proposto em novos projetos? Qual o principal motivo da sua resposta? 
Com relação a última pergunta, 100\% dos entrevistados afirmaram que sim, gostariam de utilizar o processo em um novo projeto. Entre outras respostas mencionadas na última pergunta, destacaram-se como motivação da resposta: "não é um processo oneroso"; "facilita o mapeamento dos requisitos e melhora o entendimento para ambas as partes, analista e cliente"; "agrega valor ao projeto"; "facilidade de utilização e entendimento do diagrama"; "o NTI não possui um processo para tal atividade"; "geração de documentos de requisitos"; "identificação dos relacionamentos entre requisitos". O Analista de Sistemas P12 fez uma ressalva quanto ao esforço necessário para criar manualmente o Diagrama de Requisitos da SysML para projetos com um número alto de requisitos.

Em resposta à questão Q3 da Tabela 9, a análise das respostas à entrevista sugere que em termos de resultado geral do processo, envolvendo a melhora na comunição entre os stakeholders e definição da documentação de requistos em nível de usuário, os Analistas de Sistemas sentem-se satisfeitos com os resultados alcançados. Os entrevistados, em sua maioria, indicam que o processo pode melhorar a realização de suas atividades na instituição e se sentem capazes de executar o processo pela sua facilidade de entendimento e clareza na documentação do processo. Por fim, os Analistas de Sistemas sentem-se motivados a utilizar o processo em projetos futuros. Diante das respostas analisadas e salvo suas ressalvas, pode-se inferir que o resultado geral do processo é satisfatório na visão dos Analistas de Sistemas participantes deste estudo.

\subsubsection{Ameaças à Validade}

Mesmo diante dos resultados obtidos, este estudo apresenta ameaças à sua validade que não podem ser desconsideradas. Desta forma, são apresentados três tipos de ameaças encontradas.

Validade interna: devido ao fator humano e contexto participativo da pesquisaação, as respostas ao questionário podem indicar um viés dos participantes em beneficiar a pesquisa. Outra ameaça é o envolvimento dos pesquisdores e participantes que podem erroneamente inferir que podem prejudicar os pesquisadores e os resultados da pesquisa em suas respostas ao questionário caso as respostas não sejam positivas. Outro ponto refere-se à questão de estar propondo tanto um novo processo quanto a introdução de outra forma de modelagem de requisitos usando a linguagem SysML. Estas são duas contribuições diferentes que podem ter impacto entre si.

Validade externa: devido ao contexto específico da intervenção realizada por meio deste estudo, não se deve generalizar os resultados aqui obtidos.

Validade de conclusão: não podemos afirmar que os mesmos resultados podem ser obtidos caso um novo estudo desta mesma metodologia e com objetivos semelhantes seja realizado, devido ao contexto restrito em que foi desenvolvido este estudo. Todavia, acreditamos que nossos resultados são válidos e que um novo estudo de pesquisa-ação pode ser praticado e alcançar resultados satisfatórios seguindo as atividades indicadas para condução de um estudo de pesquisa-ação conforme sugere a literatura discutida ao longo deste estudo. Não podemos classificar a etapa de avaliação deste estudo como um 
experimento controlado, mesmo seguindo uma estrutura experimental para realização da avaliação. $\mathrm{O}$ intuito de utilizar tal estrutura foi motivado pela necessidade de mitigar uma série de ameaças provocadas pelo ambiente em que foi realizada a pesquisa-ação.

\section{Conclusão}

A discussão acerca dos problemas enfrentados pelas empresas e instituições públicas no contexto da Engenharia de Requisitos ultrapassa os limites das soluções tecnológicas. Para muitas organizações, a solução desses problemas passa pela necessidade de capacitação específica em requisitos de software para seus profissionais e/ou pela transformação cultural do ambiente produtivo, realizada pela implantação de processos de negócio capazes de melhorar a eficácia e a qualidade das atividades desenvolvidas. Criar uma documentação de requisitos que seja completa e de fácil entendimento por todos os envolvidos em um projeto de software ainda se destaca como um problema a ser resolvido na ER. A produção acadêmica recente tem proposto soluções pouco investigadas na prática quanto a sua eficácia em diferentes tipos de ambientes organizacionais.

Neste estudo foi realizada uma intervenção, por meio da metodologia da pesquisaação, para solução de problemas relacionados à documentação de requisitos em nível de usuário em projetos do Núcleo de Tecnologia da Informação da Universidade Federal de Sergipe. Os problemas enfrentados pela instituição nos seus projetos de software motivou a realização deste estudo.

Os resultados obtidos na avaliação sugerem ampla aceitação dos participantes quanto à utilização do processo em novos projetos do NTI. A eficácia do processo também é comprovada por meio dos resultados alcançados. O template para documentação de requisitos proposto atendeu as necessidades da instituição e a SysML por meio do seu Diagrama de Requisitos e da Tabela de Requisitos se mostrou eficaz na documentação dos relacionamentos entre requisitos. As atividades e os artefatos propostos no processo atenderam as necessidades dos participantes do estudo, incluindo as ferramentas utilizadas na realização das tarefas. O processo foi incorporado ao dia a dia da instituição e será reavaliado, após as conclusões dos projetos, pela coordenação do NTI junto com os analistas de sistemas para realizar, se necessário, melhorias nas suas atividades.

Os resultados apresentados são evidências de uma intervenção realizada com sucesso. A pesquisa-ação mostrou-se uma metodologia capaz de integrar a academia e a indústria ou o setor público para condução de pesquisas práticas em Engenharia de Software.

\subsection{Contribuições deste estudo}

Este estudo possui relevância científica e prática, pois fornece experiências para a academia por meio da realização de estudos em projetos reais e ajuda na avaliação de práticas propostas na literatura e pouco utilizadas na indústria. Este estudo apresentou diversas contribuições para a Engenharia de Requisitos, conforme destacamos a seguir.

Uma contribuição deste trabalho foi o exercício da metodologia da pesquisa-ação em um estudo no contexto da Engenharia de Requisitos. A metodologia se mostrou importante no envolvimento entre pesquisadores e participantes e possibilitou um desenvolvimento evolutivo da pesquisa e resolução do problema. Há uma necessidade de mais 
estudos práticos na academia e a pesquisa-ação se mostrou neste estudo uma forma de alcançar esse objetivo.

Este estudo possibilitou a transferência de tecnologia entre academia e o setor público, materializado em um processo para ser utilizado na Engenharia de Requisitos de novos projetos de desenvolvimento de software no Núcleo de Tecnologia da Informação de Universidade Federal no Brasil.

Este estudo possibilitou a aplicação da SysML para modelagem de requisitos de software no setor público. Esse é um contexto pouco explorado na academia no tocante a eficácia da SysML para documentação de requisitos. Esse estudo contribui trazendo uma avaliação da utilização prática da SysML na perspectiva de requisitos em nível de usuário em um projeto real dentro de uma instituição pública.

\subsection{Limitações deste estudo}

Embora os resultados obtidos neste trabalho tenham se mostrado satisfatórios, foram encontradas limitações durante o desenvolvimento deste estudo.

A abordagem qualitativa utilizada limita a validade dos nossos resultados. Os resultados do estudo estão ligados aos julgamentos e interpretações dos envolvidos, o que pode ter influenciado nos resultados. Devido ao método flexível proposto pela pesquisaação, outro problema encontrado refere-se ao processo de coleta e análise dos dados. Para aumentar a validade e qualidade dos dados foram realizadas etapas de avaliação em todos os ciclos de pesquisa-ação, em um esforço para aumentar sua credibilidade por meio da análise realizada em diversos momentos do estudo.

Outra limitação encontrada refere-se ao tempo necessário para realizar estudos desta natureza. O prazo e o tamanho do estudo não permitiu uma avaliação completa do processo. Para validação completa seria necessário não somente uma avaliação da eficácia, mas também uma avaliação da eficiência do processo por meio de uma análise quantitativa da evolução do processo e os efeitos do processo nas demais etapas do ciclo de vida do desenvolvimento do software.

Embora o estudo realizado tenha sido concluído com uma análise da eficácia do processo, novos estudos são necessários para avaliar a eficiênçia e o impacto do processo em relação às outras atividades do ciclo de vida do desenvolvimento de software, além de analisar a perspectiva do Cliente e dos Gestores em relação ao processo.

\section{Referências}

Amyot, D., Anda, A. A., Baslyman, M., Lessard, L., and Bruel, J.-M. (2016). Towards Improved Requirements Engineering with SysML and the User Requirements Notation. In Requirements Engineering Conference (RE), 2016 IEEE 24th International, pages 329-334. IEEE.

Amyot, D. and Mussbacher, G. (2011). User Requirements Notation: The First Ten Years, The Next Ten Years. JSW, 6(5):747-768.

Asghar, A. R., Bhatti, S. N., Tabassum, A., and Shah, S. A. A. S. (2017). The Impact of Analytical Assessment of Requirements Prioritization Models: An Empiri- 
cal Study. International Journal of Advanced Computer Science and Applications (IJACSA), 8(2):303-313.

Basili, V. R. and Weiss, D. M. (1984). A Methodology for Collecting Valid Software Engineering Data. IEEE Transactions on Software Engineering, 10(6):728-738.

Berry, D. M. (2004). The Inevitable Pain of Software Development: Why There is no Silver Bullet. In Radical Innovations of Software and Systems Engineering in the Future, pages 50-74. Springer.

Bizagi (2018). (bizagi.com, 2018).

Braude, E. and Bernstein, M. (2016). Software Engineering: Modern Approaches, Second Edition. John Wiley, USA.

Brooks, F. P. (1987). No Silver Bullet. IEEE Computer, 20(4):10-19.

Buede, D. and Miller, W. (2016). The Engineering Design of Systems: Models and Methods. Wiley Series in Systems Engineering and Management. Wiley, USA.

CBOK, B. (2013). Guide to the Business Process Management Common Body of Knowledge (BPM CBOK) 3.0.

Chang, C.-H., Lu, C.-W., Yang, W. P., Chu, W. C.-C., Yang, C.-T., Tsai, C.-T., and Hsiung, P.-A. (2014). A SysML Based Requirement Modeling Automatic Transformation Approach. In Computer Software and Applications Conference Workshops (COMPSACW), 2014 IEEE 38th International, Sweden, pages 474-479. IEEE.

Chinosi, M. and Trombetta, A. (2012). BPMN: An Introduction to the Standard. Computer Standards \& Interfaces, 34(1):124-134.

Cui, X. and Paige, R. (2012). An Integrated Framework for System/Software Requirements Development Aligning with Business Motivations. In Computer and Information Science (ICIS), 2012 IEEE/ACIS 11th International Conference on, pages 547552. IEEE.

de Sousa, T. L., Venson, E., da Costa Figueiredo, R. M., Kosloski, R. A., and Junior, L. C. M. R. (2016). Using Scrum in Outsourced Government Projects: An Action Research. In System Sciences (HICSS), 2016 49th Hawaii International Conference on, pages 5447-5456. IEEE.

Dos Santos, P. S. M. and Travassos, G. H. (2011). Action Research can Swing the Balance in Experimental Software Engineering. In Advances in computers, volume 83, pages 205-276. Elsevier.

Elden, M. and Chisholm, R. F. (1993). Emerging Varieties of Action Research: Introduction to the Special Issue. Human relations, 46(2):121-142.

Ellis, K. and Berry, D. M. (2013). Quantifying the Impact of Requirements Definition and Management Process Maturity on Project Outcome in Large Business Application Development. Requirements Engineering, pages 1-27.

Fernández, D. M., Wagner, S., Kalinowski, M., Schekelmann, A., Tuzcu, A., Conte, T., Spinola, R., and Prikladnicki, R. (2015). Naming the Pain in Requirements Engineering: Comparing Practices in Brazil and Germany. IEEE Software, 32(5):16-23. 
Friedenthal, S., Moore, A., and Steiner, R. (2008). Omg Systems Modeling Language $\left(\mathrm{OMG}\right.$ SysML ${ }^{\mathrm{TM}}$ ) Tutorial. In INCOSE international symposium, volume 18, pages 1731-1862. Wiley Online Library.

Geiger, M., Harrer, S., Lenhard, J., and Wirtz, G. (2018). BPMN 2.0: The State of Support and Implementation. Future Generation Computer Systems, 80:250-262.

Hall, T., Beecham, S., and Rainer, A. (2002). Requirements Problems in Twelve Software Companies: An Empirical Analysis. IEE Proceedings-Software, 149(5):153-160.

Hampson, K. (2015). Technical Evaluation of the Systems Modeling Language (SysML). Procedia Computer Science, 44:403-412.

Hutchinson, J., Whittle, J., and Rouncefield, M. (2014). Model-Driven Engineering Practices in Industry: Social, Organizational and Managerial Factors that lead to Success or Failure. Science of Computer Programming, 89:144-161.

Hutchinson, J., Whittle, J., Rouncefield, M., and Kristoffersen, S. (2011). Empirical Assessment of MDE in Industry. In Software Engineering (ICSE), 2011 33rd International Conference on, pages 471-480. IEEE.

ISO, I. (2011). IEEE. 29148: 2011-Systems and Software Engineering-Requirements Engineering. Technical report, Technical report.

Jouault, F. and Kurtev, I. (2005). Transforming Models with ATL. In International Conference on Model Driven Engineering Languages and Systems, pages 128-138. Springer.

Khan, J. A., Rehman, I. U., Khan, Y. H., Khan, I. J., and Rashid, S. (2015). Comparison of Requirement Prioritization Techniques to Find Best Prioritization Technique. International Journal of Modern Education and Computer Science, 7(11):53.

Kitchenham, B. (2004). Procedures for Performing Systematic Reviews. Keele, UK, Keele University, 33(2004):1-26.

Laplante, P. A. (2013). Requirements Engineering for Software and Systems. CRC Press, USA.

Latum, F. V., Solingen, R. V., Oivo, M., Hoisl, B., Rombach, D., and Ruhe, G. (1998). Adopting GQM based Measurement in an Industrial Environment. IEEE software, 15(1):78-86.

Leopold, H., Mendling, J., and Günther, O. (2016). Learning from Quality Issues of BPMN Models from Industry. IEEE Software, 33(4):26-33.

Mafra, P., Kalinowski, M., Fernández, D. M., Felderer, M., and Wagner, S. (2016). Towards Guidelines for Preventing Critical Requirements Engineering Problems. In Software Engineering and Advanced Applications (SEAA), 2016 42th Euromicro Conference on, pages 25-29. IEEE.

McKay, J. and Marshall, P. (2001). The Dual Imperatives of Action Research. Information Technology \& People, 14(1):46-59.

Muşat, L., Hübl, M., Buzo, A., Pelz, G., Kandl, S., and Puschner, P. (2016). Semiformal Representation of Requirements for Automotive Solutions Using SysML. In 
Languages, Design Methods, and Tools for Electronic System Design, pages 57-81. Springer.

Oliveira, F., Goldman, A., and Santos, V. (2015). Managing Technical Debt in Software Projects using Scrum: An Action Research. In Agile Conference (AGILE), 2015, pages 50-59. IEEE.

OMG, B. P. M. (2011). Notation (BPMN). FTF Beta, 1.

Paech, B., Koenig, T., Borner, L., and Aurum, A. (2005). An Analysis of Empirical Requirements Engineering Survey Data. In Engineering and Managing Software Requirements, pages 427-452. Springer Berlin Heidelberg.

Papyrus (2018). (www.eclipse.org/papyrus, 2018).

Petersen, K., Gencel, C., Asghari, N., Baca, D., and Betz, S. (2014). Action Research as a Model for Industry-Academia Collaboration in the Software Engineering Context. In Proceedings of the 2014 International Workshop on Long-term Industrial Collaboration on Software Engineering, WISE '14, pages 55-62, New York, NY, USA. ACM.

Pillat, R. M., Oliveira, T. C., Alencar, P. S., and Cowan, D. D. (2015). Bpmnt: A BPMN Extension for Specifying Software Process Tailoring. Information and Software Technology, 57:95-115.

Pohl, K. (2010). Requirements Engineering: Fundamentals, Principles, and Techniques. Springer Publishing Company, Incorporated, USA, 1st edition.

Pressman, R. and Maxim, B. (2016). Engenharia de Software- $8^{a}$ Edição. McGraw Hill, Brasil.

Ramasubbu, N. (2014). Governing Software Process Improvementsin Globally Distributed Product Development. IEEE Transactions on Software Engineering, 40(3):235250.

Redmine (2018). (www.redmine.org, 2018).

Scanniello, G., Staron, M., Burden, H., and Heldal, R. (2014). On the Effect of Using SysML Requirement Diagrams to Comprehend Requirements: Results from two Controlled Experiments. In Proceedings of the 18th International Conference on Evaluation and Assessment in Software Engineering, page 49. ACM.

Soares, M. S. and Cioquetta, D. S. (2012). Analysis of Techniques for Documenting User Requirements. In International Conference on Computational Science and Its Applications, pages 16-28. Springer.

Soares, M. S., Vrancken, J., and Verbraeck, A. (2011). User Requirements Modeling and Analysis of Software-Intensive Systems. Journal of Systems and Software, 84:328339.

Soares, M. S. and Vrancken, J. L. (2008). Model-Driven User Requirements Specification using SysML. JSW, 3(6):57-68.

Sommerville, I. (2011). Engenharia de Software. Pearson Prentice Hall, USA. 
Störrle, H. (2017). How are Conceptual Models used in Industrial Software Development?: A Descriptive Survey. In Proceedings of the 21st International Conference on Evaluation and Assessment in Software Engineering, pages 160-169. ACM.

SysML, O. (2015). OMG Systems Modeling Language.

Thiollent, M. (2011). Metodologia da Pesquisa-ação. In Metodologia da Pesquisa-ação. Cortez, Brasil.

Tripp, D. (2005). Action Research: A Methodological Introduction. Educacao e pesquisa, 31(3):443-466.

Van Lamsweerde, A. (2000). Requirements Engineering in the Year 00: A Research Perspective. In Proceedings of the 22nd international conference on Software engineering, pages 5-19. ACM.

Wiegers, K. and Beatty, J. (2013). Software Requirements. Developer Best Practices. Pearson Education, USA.

Wohlin, C., Runeson, P., Höst, M., Ohlsson, M. C., Regnell, B., and Wesslén, A. (2012). Experimentation in Software Engineering. Springer Science \& Business Media. 
APÊNDICE A - ARTEFATOS GERADOS NO PROCESSO 


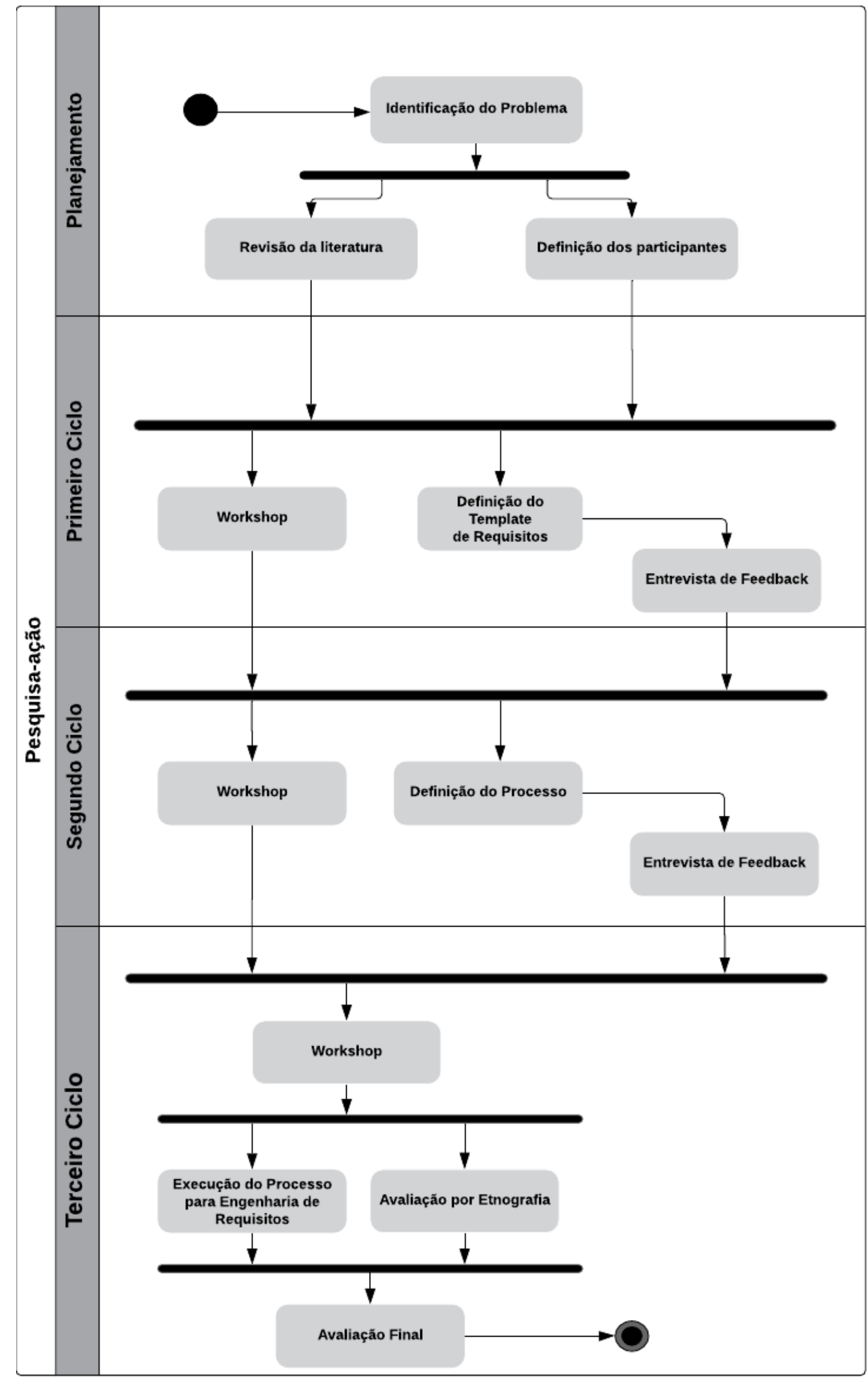

Figura 8. Atividades - Ciclos de Pesquisa-ação

iSys: Revista Brasileira de Sistemas de Informação (iSys: Brazilian Journal of Information Systems) http://seer.unirio.br/index.php/isys/ 


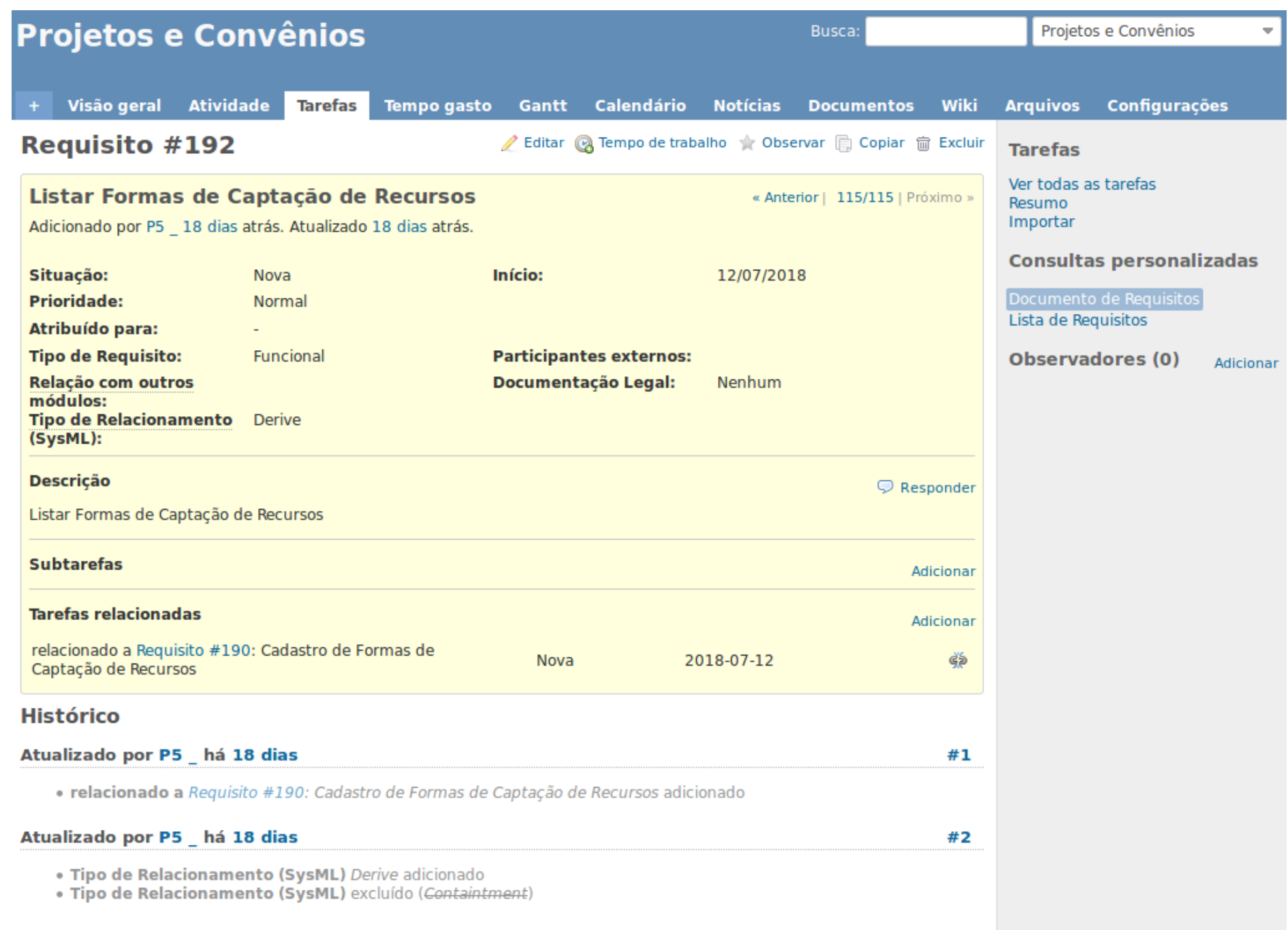

Figura 9. Exemplo: Registrar dados do requisito (Redmine)- Projetos e Convênios 


\section{LISTA DE STAKEHOLDERS}

\begin{tabular}{|l|}
\hline PROJETO \\
\hline Projetos e Convênios \\
\hline ANALISTA DE SISTEMAS \\
\hline P4, P5, P9 e P10 \\
\hline
\end{tabular}

\begin{tabular}{|l|l|}
\hline ID: 01 & NOME : Cárlos Rabarto \\
\hline CARGO/FUNÇĀO: Coordenador & $\begin{array}{l}\text { PODER DE DECISÃO: } \\
\text { (x)Alto } \\
\text { ( ) Médio } \\
\text { bai xo }\end{array}$ \\
\hline E-MAIL: @ufs.br & TELEFONE: 9898-9898 \\
\hline SETOR: Coordenação de programas, convênios e contratos & $\begin{array}{l}\text { PARTICIPA DA ACEITAÇÃO? } \\
\text { (x)Sim ( )Não }\end{array}$ \\
\hline $\begin{array}{l}\text { OBJETIVOS E INTERESSES: Objetiva a construção de um sistema para o gerenciamento de } \\
\text { contratos e convênios na UFS. }\end{array}$ \\
\hline
\end{tabular}

\begin{tabular}{|l|l|l|}
\hline ID: 02 & NOME : Jose & DATA: \\
\hline CARGO/FUNÇĀO: Técnico administrativo & $\begin{array}{l}\text { PODER DE DECISÃO: } \\
\text { ()Alto } \\
\text { (x)Médio } \\
\text { ()bai xo }\end{array}$ \\
\hline E-MAIL: & TELEFONE: 9998-9898 \\
\hline SETOR: Coordenação de programas, convênios e contratos & $\begin{array}{l}\text { PARTICIPA DA ACEITAÇÃO? } \\
\text { (x)Sim ( )Não }\end{array}$ \\
\hline $\begin{array}{l}\text { OBJETIVOS E INTERESSES: Objetiva a construção de um sistema para o gerenciamento de } \\
\text { contratos e convênios na UFS. }\end{array}$ \\
\hline
\end{tabular}

Figura 10. Exemplo: Lista de Stakeholders - Projetos e Convênios 


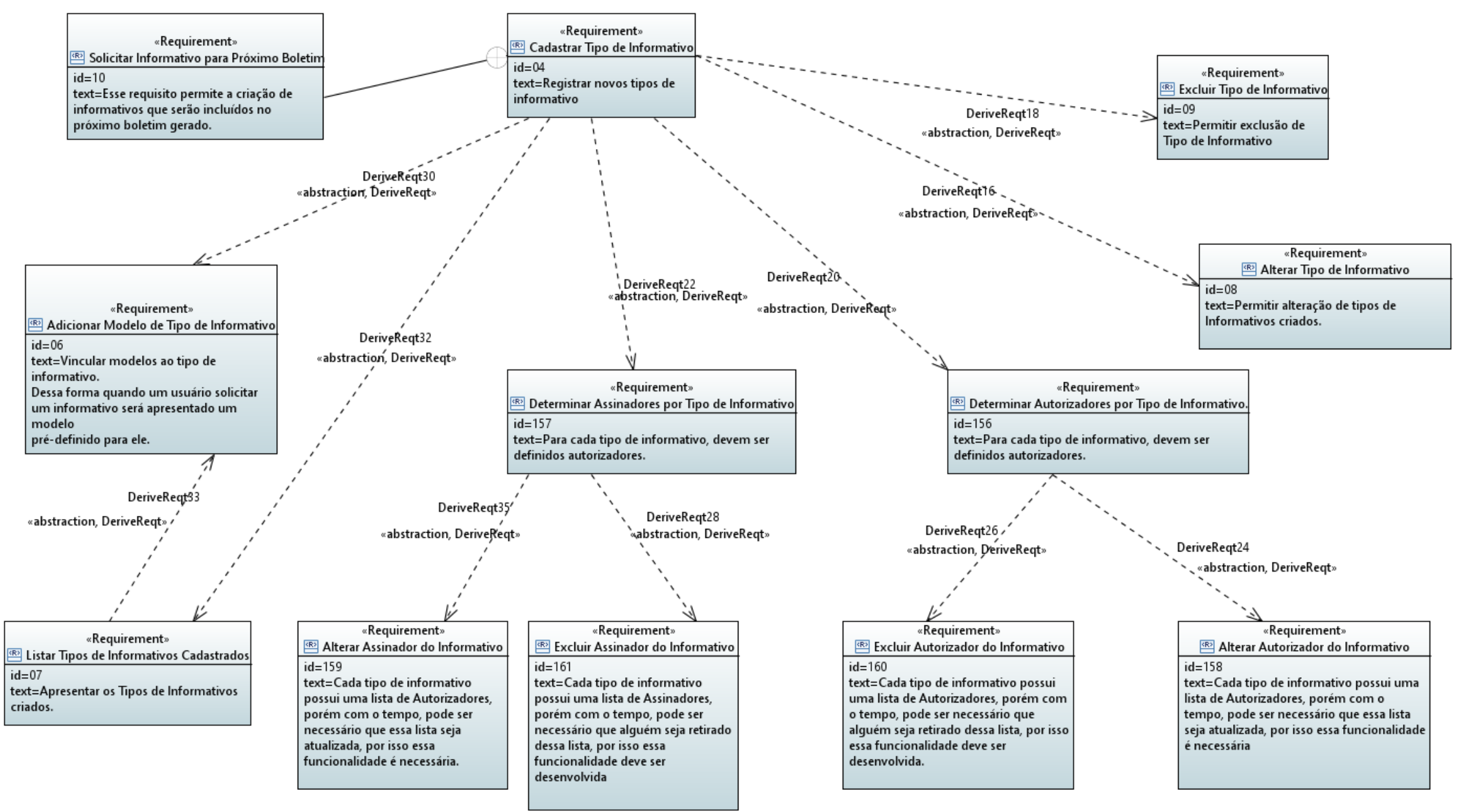

Figura 11. Exemplo: Diagrama de Requisitos da SysML (Papyrus) - Boletim de Serviços 


\section{LISTA DE CONFLITOS}

\begin{tabular}{|l|}
\hline PROJETO: \\
\hline Boletim de Serviços \\
\hline ANALISTA DE SISTEMAS: \\
\hline P3 e P6 \\
\hline
\end{tabular}

\begin{tabular}{|l|l|}
\hline ID: 1 & DATA: \\
\hline $\begin{array}{l}\text { DESCRIÇÃO DO CONFLITO: Adicionar Link no Boletim para Consultar Informativos Assinados } \\
\text { Digitalmente }\end{array}$ \\
\hline REQUISITOS ENVOLVIDOS (ID): 199 \\
\hline DECISÃO: Ficou decidido que era desnecessária a implementação dessa funcionalidade \\
\hline
\end{tabular}

\begin{tabular}{|l|l|}
\hline ID: 2 & DATA: \\
\hline DESCRIÇÃO DO CONFLITO: Permitir Vincular Alterações/Revogações em Resoluções a Serem Publicadas \\
\hline REQUISITOS ENVOLVIDOS (ID): 194 e 152 \\
\hline $\begin{array}{l}\text { DECISÃO: Ficou decidido que o R-152 continuaria sendo considerado, já que tanto o R-194 e R-152 } \\
\text { descrevem a mesma funcionalidade }\end{array}$ \\
\hline
\end{tabular}

\begin{tabular}{|l|l|}
\hline ID: 3 & DATA: \\
\hline $\begin{array}{l}\text { DESCRIÇÃO DO CONFLITO: Despublicar Informativo - os usuários inicialmente queriam a implementação } \\
\text { dessa funcionalidade, porém havia uma questão quanto a legalidade dessa medida }\end{array}$ \\
\hline REQUISITOS ENVOLVIDOS (ID): 137 \\
\hline $\begin{array}{l}\text { DECISÃO: Ficou decidido que essa funcionalidade deveria ficar desabilitada, devido ao risco de que ela } \\
\text { fosse de encontro ao princípio da legalidade, previsto, no Art } 37 \text { da Constituição Federal }\end{array}$ \\
\hline
\end{tabular}

\begin{tabular}{|l|l|}
\hline ID: 4 & DATA: \\
\hline $\begin{array}{l}\text { DESCRIÇÃO DO CONFLITO: Editar Boletim Publicado - os usuários inicialmente queriam a implementação } \\
\text { dessa funcionalidade, porém havia uma questão quanto a legalidade dessa medida }\end{array}$ \\
\hline REQUISITOS ENVOLVIDOS (ID): 135 \\
\hline $\begin{array}{l}\text { DECISÃO: Ficou decidido que essa funcionalidade deveria ficar desabilitada, devido ao risco de que ela } \\
\text { fosse de encontro ao princípio da legalidade, previsto, no Art } 37 \text { da Constituição Federal }\end{array}$ \\
\hline
\end{tabular}

Figura 12. Exemplo: Lista de Conflitos - Boletim de Serviços 


\section{CHECKLIST PARA VALIDAÇÃO DOS REQUISITOS EM NÍVEL DE USUÁRIO}

\begin{tabular}{|c|c|c|}
\hline \multicolumn{3}{|l|}{ PROJETO } \\
\hline \multicolumn{3}{|l|}{ Jubilamento } \\
\hline ANALISTA DE SISTEMAS & DATA & \\
\hline \multicolumn{3}{|l|}{$\mathrm{P} 12$} \\
\hline \multirow[t]{2}{*}{ CARACTERISTICAS DE QUALIDADE } & & \\
\hline & Sim & Não \\
\hline \multicolumn{3}{|l|}{ Essencial: } \\
\hline $\begin{array}{l}\text { Os requisitos definidos são essenciais para implementação do software por definirem uma } \\
\text { capacidade essencial, característica, restrição ou fator de qualidade? }\end{array}$ & $\mathrm{x}$ & \\
\hline \multicolumn{3}{|l|}{ Independente de implementação: } \\
\hline Os requisito evitam colocar restrições desnecessárias na arquitetura? & $\mathrm{X}$ & \\
\hline \multicolumn{3}{|l|}{ Sem ambiguidade: } \\
\hline Os requisitos estão descritos de tal forma que podem ser interpretados de uma única maneira? & $\mathrm{x}$ & \\
\hline Os requisitos estão descritos de forma compreensivel pelos stakeholders? & & $\mathrm{x}$ \\
\hline \multicolumn{3}{|l|}{ Consistente: } \\
\hline Os requisitos estão livres de conflitos? & $\mathrm{x}$ & \\
\hline Os requisitos estão descritos de acordo com o template e seus atributos? & $\mathrm{x}$ & \\
\hline \multicolumn{3}{|l|}{ Completo: } \\
\hline Os requisitos estão descritos de forma que podem ser mensurados? & & $\mathrm{X}$ \\
\hline $\begin{array}{l}\text { O conjunto de requisitos não precisa de dados adicionais porque contêm tudo o que é } \\
\text { pertinente para a definição do software ou funcionalidade especificada? }\end{array}$ & & $\mathrm{x}$ \\
\hline $\begin{array}{l}\text { O documento de requisitos inclui todas as necessidades conhecidas dos stakeholders ou do } \\
\text { sistema? }\end{array}$ & $\mathrm{x}$ & \\
\hline $\begin{array}{l}\text { Os requisitos descritos descrevem as características necessárias para atender às necessidades } \\
\text { dos stakeholders? }\end{array}$ & $\mathrm{x}$ & \\
\hline \multicolumn{3}{|l|}{ Singular: } \\
\hline Os requisitos possuem um identificador único? & $\mathrm{x}$ & \\
\hline Apenas um requisito foi definido? & $\mathrm{x}$ & \\
\hline \multicolumn{3}{|l|}{ Viável: } \\
\hline $\begin{array}{l}\text { Os requisitos são tecnicamente viáveis, não requerem grandes avanços tecnológicos, e se } \\
\text { encaixa dentro das restrições do sistema? }\end{array}$ & $\mathrm{x}$ & \\
\hline \multicolumn{3}{|l|}{ Rastreável: } \\
\hline Os requisitos são rastreáveis em relação aos artefatos que o antecedem? & $\mathrm{x}$ & \\
\hline Os requisitos são rastreáveis artefatos relacionados criados após sua documentação? & & $\mathrm{x}$ \\
\hline Os requisitos são rastreáveis para outros requisitos relacionados? & $\mathrm{x}$ & \\
\hline \multicolumn{3}{|l|}{ Verificável: } \\
\hline $\begin{array}{l}\text { Os requisito possuem meios que facilitem provar que o sistema satisfaz o requisito } \\
\text { Especificado? }\end{array}$ & $\mathrm{x}$ & \\
\hline Os requisitos foram priorizados? & $\mathrm{x}$ & \\
\hline \multicolumn{3}{|l|}{ Acessível: } \\
\hline $\begin{array}{l}\text { O conjunto completo de requisitos pode ser implementado por uma solução viável dentro das } \\
\text { restrições do projeto (por exemplo: custo, prazo, técnico, legal ou de qualidade)? }\end{array}$ & $\mathrm{x}$ & \\
\hline \multicolumn{3}{|l|}{\begin{tabular}{|l|l|} 
Limitado: & \\
\end{tabular}} \\
\hline $\begin{array}{l}\text { O conjunto de requisitos mantém o escopo identificado para a solução pretendida } \\
\text { sem aumentar além do que é necessário para satisfazer as necessidades dos stakeholders? }\end{array}$ & $\mathrm{x}$ & \\
\hline
\end{tabular}

Figura 13. Exemplo: Checklist de Validação - Jubilamento 
Lato Sensu - Lista de Requisitos

\begin{tabular}{|c|c|c|c|c|c|}
\hline \# & Titulo & Tipo & Tipo de Requisito & Prioridade & Autor \\
\hline \multicolumn{6}{|c|}{ Alta (4) } \\
\hline 250 & Incluir dados de financiamento da Proposta & Requisito & Funcional & Alta & $\mathrm{P} 11 \ldots$ \\
\hline 254 & Nāo permitir que o usuário altere o status do discente para 'Aprovado' se não houver mais vagas. & Requisito & Funcional & Alta & $\mathrm{P} 11$ \\
\hline 270 & Adicionar filtro na busca de Cursos & Requisito & Funcional & Alta & $\mathrm{P} 11$ \\
\hline 291 & Remover a validação que não permite que um curso possua mais docentes externos do que internos. & Requisito & Funcional & Alta & $\mathrm{P} 11 \ldots$ \\
\hline \multicolumn{6}{|c|}{ Normal (34) } \\
\hline 252 & Não permitir que a soma das cargas horárias dos docentes externos seja superior à 50\% da carga horária do curso. & Requisito & Funcional & Normal & P11_ \\
\hline 253 & Permitir a visualização detalhada das propostas de curso. & Requisito & Funcional & Normal & P11_ \\
\hline 255 & Desvincular a Data de Início de Mandato do Coordenador & Requisito & Funcional & Normal & $\mathrm{P} 11$ \\
\hline 256 & Criar o status 'Pagamento Realizado' de GRU para Processo Seletivo & Requisito & Funcional & Normal & $\mathrm{P} 11_{-}$ \\
\hline 257 & Carregar dados cadastrados pelo candidato durante o cadastro do discente & Requisito & Funcional & Normal & $\mathrm{P} 11$ \\
\hline 258 & Notificação por email de matrícula em curso & Requisito & Funcional & Normal & $\mathrm{P} 11$ \\
\hline 259 & Incluir outras opçōes nos dados do processo seletivo & Requisito & Funcional & Normal & $\mathrm{P} 11$ - \\
\hline 261 & Preencher automaticamente os campos de data na Criaçāo da Turma de Entrada & Requisito & Funcional & Normal & $\mathrm{P} 11$ \\
\hline 262 & Definir vencimento do boleto como $1^{19}$ dia útil após término das inscriçōes & Requisito & Funcional & Normal & $\mathrm{P} 11$ \\
\hline 263 & Inserir configuraçāo de GRU de Lato & Requisito & Funcional & Normal & $\mathrm{P} 11$ \\
\hline 264 & Limpar campos de "Ano" e "Períod" no formulário de Cadastro de Turma & Requisito & Funcional & Normal & $\mathrm{P} 11$ \\
\hline 265 & Adicionar item "Corpo Docente" na página pública de Curso Lato & Requisito & Funcional & Normal & $\mathrm{P} 11_{-}$ \\
\hline 266 & Listar todos alunos em "Alunos do Curso" & Requisito & Funcional & Normal & $\mathrm{P} 11$ \\
\hline 267 & Remover as opçôes de adição "Docentes que não pertencem ao programa" e "Docentes Externos" do Cadastro de Turma. & Requisito & Funcional & Normal & $\mathrm{P} 11$ \\
\hline 268 & Criar a aba Módulos na página pública de Curso Lato Sensu & Requisito & Funcional & Normal & $\mathrm{P} 11$ \\
\hline 269 & Remover a aba Turma da página pública de Curso Lato Sensu & Requisito & Funcional & Normal & $\mathrm{P} 11$ \\
\hline 272 & Visualizar a justificativa de um edital devolvido & Requisito & Funcional & Normal & $\mathrm{P} 2{ }_{-}$ \\
\hline 274 & Adicionar coluna com a Data de Submissão dos relatórios na página de consulta de Relatórios Finais. & Requisito & Funcional & Normal & $\mathrm{P} 2{ }_{-}$ \\
\hline 275 & Criar papel Bolsista & Requisito & Funcional & Normal & $\mathrm{P} 2{ }_{-}$ \\
\hline 277 & Criar relatório "Listar Quantitativo de Alunos Ativos/Matriculados por Curso". & Requisito & Funcional & Normal & $\mathrm{P} 2$ \\
\hline 278 & Criar funcionalidade para emissão de declaração de participação de bancas de TCC & Requisito & Funcional & Normal & $\mathrm{P} 7_{-}$ \\
\hline 279 & Criar funcionalidade de consulta de defesas de Lato Sensu & Requisito & Funcional & Normal & $\mathrm{P} 7$ - \\
\hline 280 & Criar relatório de docentes por curso & Requisito & Funcional & Normal & $\mathrm{P7} 7_{-}$ \\
\hline 281 & Criar relatório de coordenadores por curso & Requisito & Funcional & Normal & P7__ \\
\hline 282 & Criar relatório de demanda e vagas de Processos Seletivos & Requisito & Funcional & Normal & P7__ \\
\hline
\end{tabular}

Figura 14. Exemplo: Lista de Requisitos - Restaurante universitário 
Restaurante universitário - Documento de Requisitos

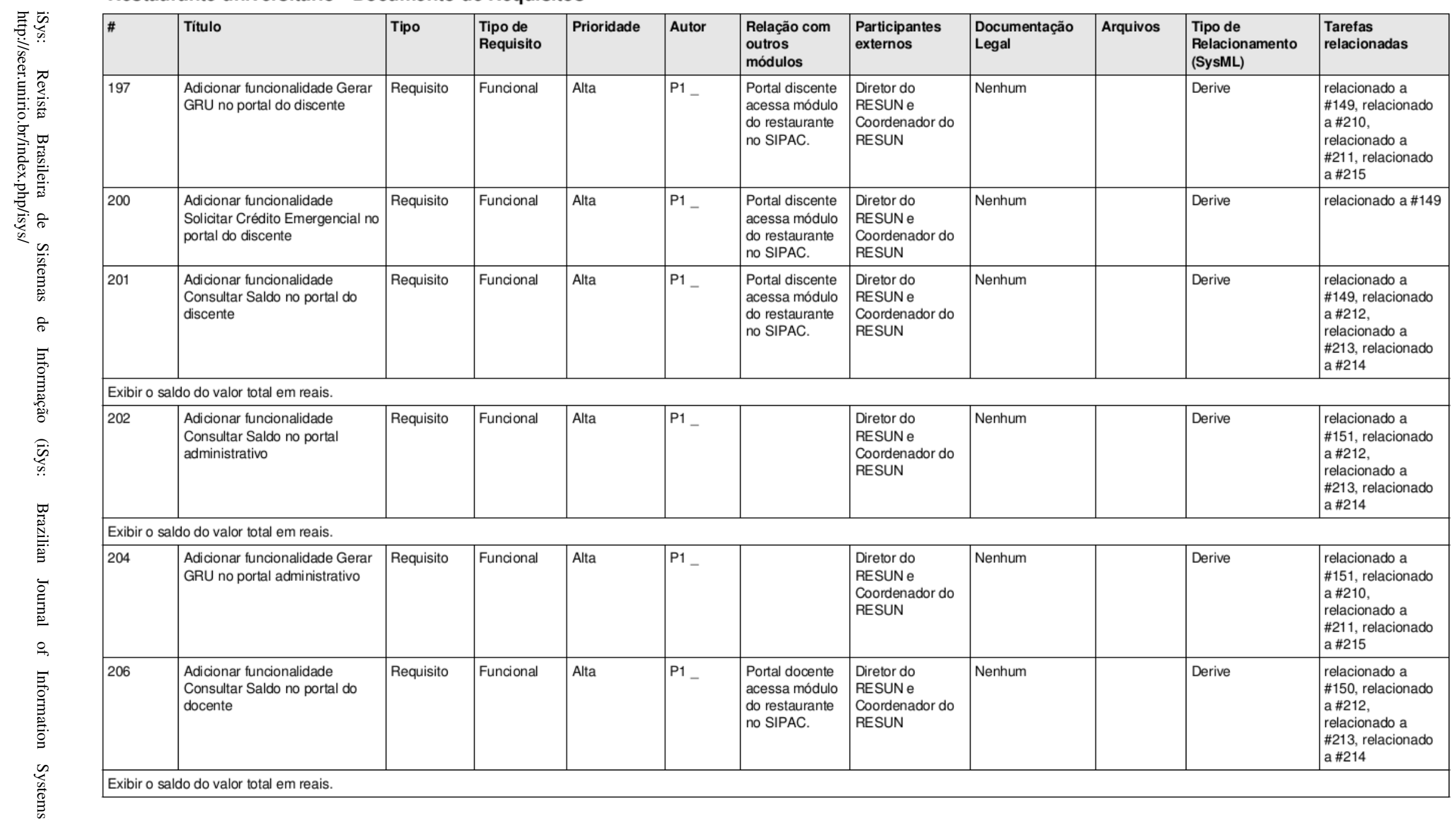

Figura 15. Exemplo: Documento de Requisitos - Restaurante universitário 